\title{
Current State of Applications of Nanocellulose in Flexible Energy and Electronic Devices
}

\begin{abstract}
Otavio Augusto Titton Dias ${ }^{1 *}$, Samir Konar ${ }^{1,2}$, Alcides Lopes Leão ${ }^{3}$, Weimin Yang ${ }^{4}$, Jimi Tjong ${ }^{1,2}$ and Mohini Sain ${ }^{1,2}$

${ }^{1}$ Centre for Biocomposites and Biomaterials Processing, University of Toronto, Toronto, ON, Canada, ${ }^{2}$ Department of Mechanical and Industrial Engineering, University of Toronto, Toronto, ON, Canada, ${ }^{3}$ College of Agricultural Sciences, São Paulo State University (Unesp), São Paulo, Brazil, ${ }^{4}$ College of Mechanical and Electrical Engineering, Beijing University of Chemical Technology, Beijing, China
\end{abstract}

Novel and unique applications of nanocellulose are largely driven by the functional attributes governed by its structural and physicochemical features including excellent mechanical properties and biocompatibility. In recent years, thousands of groundbreaking works have helped in the development of targeted functional nanocellulose for conductive, optical, luminescent materials, and other applications. The growing demand for sustainable and renewable materials has led to the rapid development of greener methods for the design and fabrication of high-performance green nanomaterials with multiple features, and consequently new challenges and opportunities. The present review article discusses historical developments, various fabrication and functionalization methods, the current stage, and the prospects of flexible energy and hybrid electronics based on nanocellulose.

Keywords: cellulose nanofibrils, cellulose nanocrystals, luminescent materials, conductive materials, films, nanocomposites, energy storage device, hybrid materials

\section{INTRODUCTION}

Nanocellulose has received significant interest due to its mechanical and optical properties, biodegradability, availability, recyclability, renewability, and low coefficient of thermal expansion. This nanomaterial, in the form of either nanofibrils or nanocrystals, has been reported as an interesting sustainable and tunable platform for the production of a variety of high value products (Kumari et al., 2014). As shown in Figure 1, there is an exponential trend in the number of citations in the area of nanocellulose. Considering the aforementioned properties of nanocellulose, transforming this renewable material into advanced materials is a crucial step toward sustainable development (Giese et al., 2014). This is feasible due to the presence of a large number of hydroxyl groups within the nanocellulose structure as well as its high surface area, high aspect ratio and great axial modulus, making this fascinating biopolymer a more attractive substrate than traditional cellulose (Wang et al., 2014; Rusmirović et al., 2017). All forms of nanocellulose are recognized as being more effective than macroscale fibers in terms of reinforcement effect and reactivity (Azeredo et al., 2010). The benefits of using renewable materials such as nanocellulose is that they can replace plastic and metal substrates in a wide range of applications and consequently diminish the pollutant residues in the environment (Huang et al., 2013). In addition, there has been rising concern over dependence on finite and depleting non-renewable petroleum and metal resources. In this sense, the design and development of green technology from advanced hybrid nanomaterials have become 


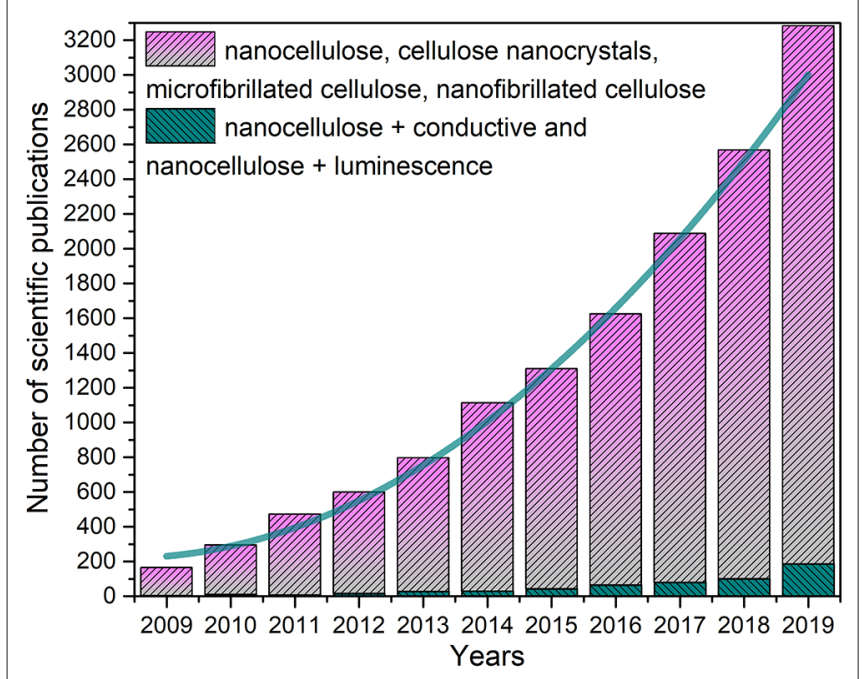

FIGURE 1 | Number of publications in the area of nanocellulose. Data analysis performed on SciFinder using terms nanocellulose, cellulose nanocrystals, microfibrillated cellulose, nanofibrillated cellulose.

a key principle of ecological sustainability (Khalil et al., 2012). Currently, there is a high demand for flexible, transparent, strong, sustainable and functional materials (Österberg et al., 2013; Abdul Khalil et al., 2014). However, despite various advantages, nanocellulose exhibits limitations that restrict its widespread applications, such as poor thermal stability, incompatibility with hydrophobic polymers and absorption of moisture. In order to employ nanocellulose for high value materials, the current challenge is providing additional functionalities via covalent modification, blending, cross-linking, polymerization, or even a combination of these methods. In this context, the presence of a large number of hydroxyl groups within the nanofiber's structure may act as a structured platform for surface modification through different substituents (Habibi, 2014). The combination of nanocellulose and carbon-based materials such as graphene, carbon nanotube and carbon dots have been advocated as a promising approach for the future of renewable electronics. In this review, we discuss the most recent developments of flexible energy and electronic devices, with special focus on luminescent and conductive materials based on nanocellulose, and potential design strategies required to expand its use in commercial applications.

\section{A Basic Introduction of Nanocellulose Brief Description of Nanocellulose Variety and Nanocellulose-Based Materials}

Cellulose is the most abundant natural polymer on Earth (Bilodeau et al., 2014). The cell wall of a fiber is built from external primary (P) and inner secondary walls (S1, S2, and S3) (Kargarzadeh et al., 2017). As shown in Figure 2, cellulose fibers can be defibrillated and/or hydrolyzed into smaller nanoscale entities known as nanocellulose, which occurs in the form of cellulose nanocrystals (CNCs) or cellulose nanowhiskers
(CNWs), and nanofibrillated celluloses (NFCs) or cellulose nanofibers (CNFs) as they are alternatively named.

Nanocellulose has been employed either in pristine form or through modification of its surface. CNFs and CNCs have distinct properties in terms of aspect ratio, surface area, and structure. CNFs possess the amorphous domains facilitating the cellulose chains motion which consequently lead to mechanical robustness and flexibility making it suitable for free-standing thin films manufacturing. On the other hand, CNCs can form a percolation network that provides a conduction path and reinforcing effects enhancing energy transfer, because of their higher crystallinity, aspect ratio and specific surface area. In addition, CNCs can act as multifunctional nanoplatforms for emerging biomedical applications and light emitting devices. The surface modification of cellulose nanoparticles is typically achieved by physical interactions or through covalently bonded of molecules with nanocellulose. CNFs in their pristine form are typically employed in hydrogels for medical applications and as reinforcing agents in hydrophilic polymers for food packaging. Hydrogels based on cellulose derivatives have numerous advantages due to their intrinsic biocompatibility and excellent gel-forming properties (Ahmed and Ikram, 2016). For hydrogels, mechanical property and cell type are crucial features for practical applications in such fields as tissue engineering (Borges et al., 2011; Martínez Ávila et al., 2014), drug delivery (Valo et al., 2013), contact lenses (Tummala, 2016), and water treatment (Gatenholm and Klemm, 2010; Lin et al., 2015). On the other hand, CNCs are rarely employed without surface modification since the absence of amorphous phase make the resulting CNC film brittle limiting the scope of the application to incorporation of CNC into hydrophilic polymers such as PVA (Jahan et al., 2018), PEO (Surov et al., 2018), and epoxy resins (Girouard et al., 2015). Due to the hydrophilic nature of nanocellulose, it can absorb water under environment conditions and may deteriorate the mechanical properties, and also impair its compatibility with hydrophobic polymers (Wang and Drzal, 2012; Farahbakhsh et al., 2015). This is evidently the biggest limitation that restricts nanocellulose utilization for advanced materials. In this context, numerous studies have been focused on the development of greener strategies for the synthesis of functional nanomaterials based on nanocellulose. As shown in Figure 3, both CNF and CNC have been modulated by different strategies in order to add new functionalities to the nanomaterials and consequently broaden their applicability. The combination of multiple components with specific features and their integration into a single device appears to be a promising approach for next-generation flexible electronics.

\section{SURFACE MODIFICATION OF NANOCELLULOSE}

The large specific surface area and the presence of a large number of hydroxyl groups within the nanocellulose structure make these nanofibers an exceptional platform for surface modification through various chemistries (Habibi, 2014). The above-mentioned features of nanocellulose offer attractive 


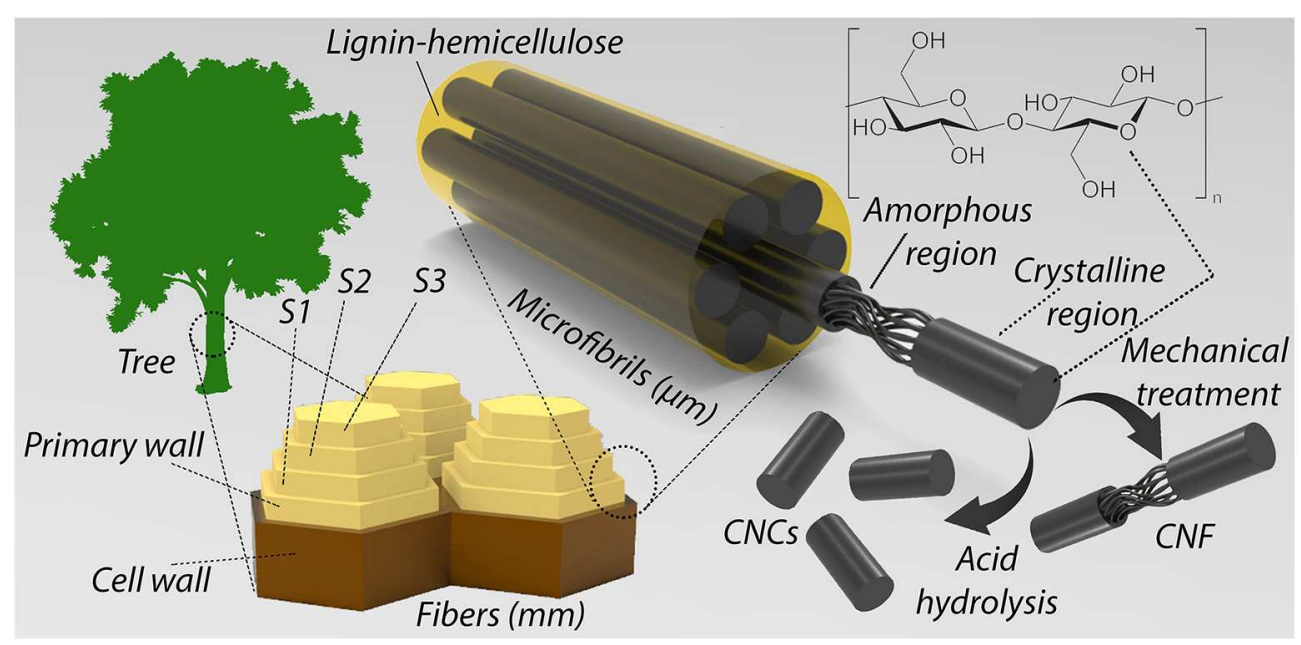

FIGURE 2 | Hierarchical structure of cellulose and schematic illustration of crystalline and amorphous regions in cellulose fiber.

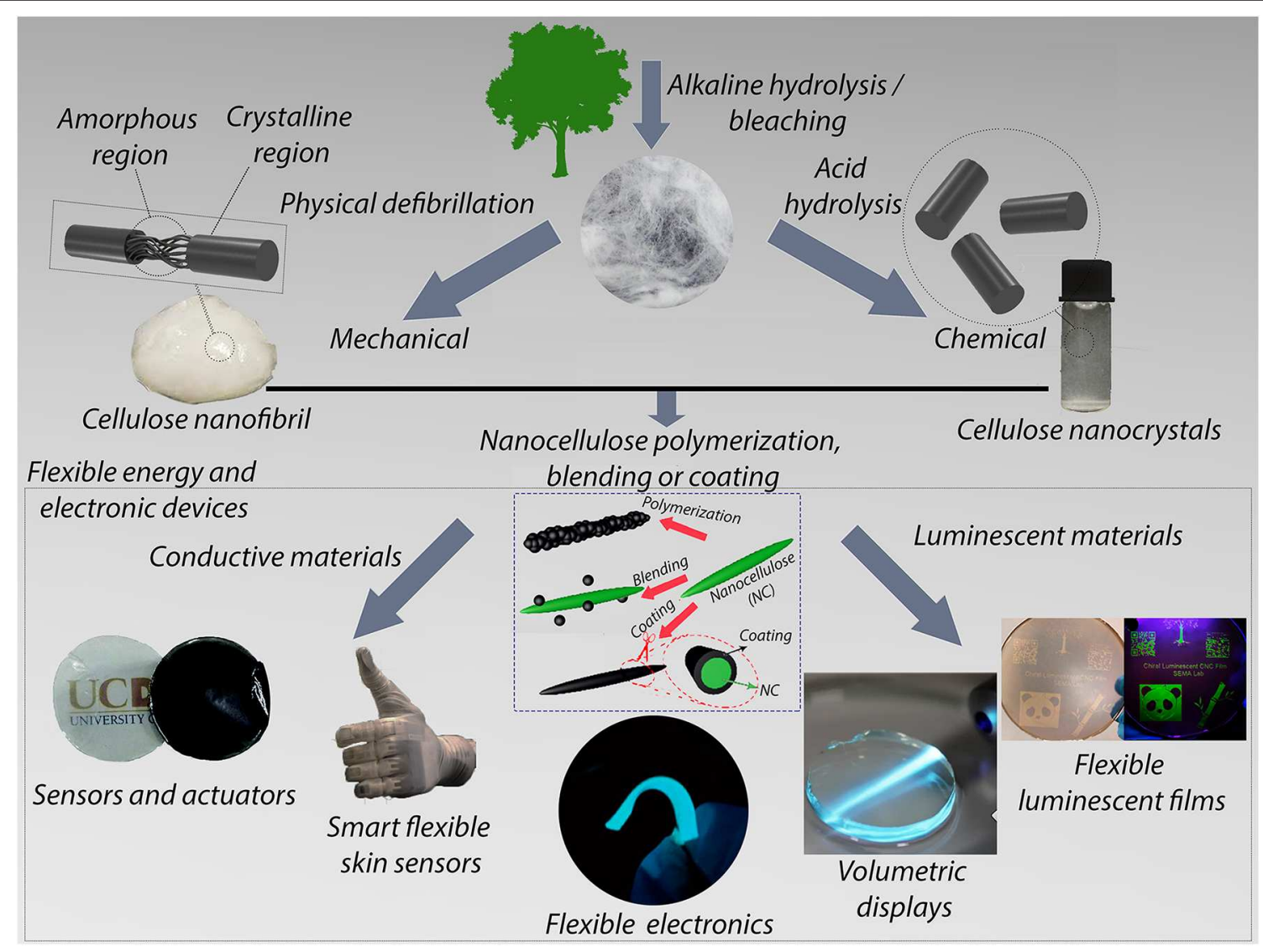

FIGURE 3 | Scheme of CNC and CNF extraction from cellulose, surface functionalization of nanocellulose for application in flexible energy and electronic materials.

strategies for targeted surface modification to incorporate almost any desired surface functionality. During the 1920s and early 1930s, the hydrophobization of cellulose surface was achieved via esterification reactions, and used for food packaging applications
(Hofmann and Reid, 1929). Over the last decades, several strategies have been employed to achieve hydrophobicity via acetylation and esterification of chitin (Nair et al., 2003), starch (Jeon et al., 1999), xylan (Peng et al., 2010), cellulose nanocrystals 
(Yuan et al., 2006), cellulose fibrils (Huang et al., 2012), and cellulose fibers (Vaca-Garcia et al., 1998). The hydrophobization of nanocellulose has been extensively explored, but studies toward more sophisticated functionalization for advanced applications have attracted more and more attention and the research is still in its early days. A variety of long-chain aliphatic compounds have been grafted on CNFs and CNCs via different techniques in order to reduce moisture absorption (Sethi et al., 2018), enhance interfacial affinity between nanofibers and resins (Tan et al., 2015; Yoo and Youngblood, 2016; Trinh and Mekonnen, 2018), and improve thermal stability (Sharma and Deng, 2016). Over the years, more sophisticated products based on cellulose derivatives have started to be considered as part of next generation technology. Recently, breakthrough products based on nanocellulose such as artificial skin, biosensors, stretchable circuits, and volumetric displays have been extensively investigated. To achieve this goal, it is necessary to modify cellulose structure and give it new characteristics. The concept of creating ion exchangeable carboxyl groups via TEMPO-mediated oxidation on nanocellulose surface have been employed by several authors (Cheng et al., 2016; Wei et al., 2016; Raghuwanshi and Garnier, 2019; Tao et al., 2020; Xu H. et al., 2020; Zeng et al., 2020; Zhang et al., 2020a,b; Zhu et al., 2020). TEMPO-oxidized nanocellulose (TONC) is recognized as a potential platform for emulsifiers (Goi et al., 2019), carbon dot anchoring (Jiang et al., 2016), fluorescent sensors (Wang et al., 2020b), conductive devices (Zhang et al., 2020b), and contributing to lower thermal expansion of materials (Fukui et al., 2018). The preparation of TONCs has therefore opened up the possibility of producing novel functional materials (Yang et al., 2018). Alternatively, nanocellulose has been modified by grafting technique either via one- (Vadakkekara et al., 2020) or two steps methods (Anirudhan and Rejeena, 2014; Mandal and Chakrabarty, 2015). Graft polymerization of vinyl monomers on cellulose structures, for example, can provide active sites for the attachment of desired functional groups (Kumari et al., 2014; Tong et al., 2020). Chemical and physical cross-linking have been employed for improvement of certain characteristics such as moisture sensitivity of nanocellulose-based materials (Sharma and Deng, 2016) and for the fabrication of fascinating materials such as flexible aerogels (Wu et al., 2019; Shahzamani et al., 2020). Functional coating on the nanofiber surfaces has also been investigated by evaluating the adhesion between nanofiber and a variety of nanoparticles (Wang Z. et al., 2019). Core-shell tannic acid and dopamide coatings on CNFs are among the recent methods for nanocellulose functionalization (Nguyen et al., 2016; Wang et al., 2017).

\section{NANOCELLULOSE DERIVED CONDUCTIVE MATERIALS}

Conductive materials predominantly contain metal particles, carbon materials, and conductive polymers. Nanocellulose can be combined with these conductive materials to fabricate conductive composites with high mechanical strength, stiffness, foldability and flexibility (Pottathara et al., 2016). The fabrication of nanocellulose-based conductive composite has been achieved mostly by surface grafting and blending of conductive species and nanocellulose (Ko et al., 2017). The surface grafting method is widely employed to covalently incorporate conductive materials onto nanocellulose as biotemplate. On the other hand, blending method is used to mix different materials in which the strength and charge-transfer of individual materials will be controlled by the physical interaction between blend components. Currently, conductive carbon nanomaterials and metallic nanoparticles are often blended with nanocellulose to produce conductive hybrid materials (Du et al., 2017). However, more sophisticated techniques have been developed to fabricate nanocellulose-based conducting materials.

\section{Combination of Nanocellulose and Conductive Polymers}

Nanocellulose is a promising sustainable material for electronics in combination with conducting polymers (Zhang et al., 2013). Green and biodegradable flexible conducting polymers have been attracting attention for potential applications in electrodes and display devices (Shi et al., 2013). Self-healing, flexible and biocompatible electroconductive hydrogel based on nanocellulose has been fabricated to be employed in implantable electronic devices (Han et al., 2019a). The poor solubility of conjugated monomers such pyrrole and aniline in organic solvents typically leads to aggregate formation and consequently brittle materials (Sakakibara and Rosenau, 2012). In this context, the combination of the ecofriendly attributes, strength, and flexibility of the nanocellulose, along with the conductivity and thermal stability of the conducting polymers has opened opportunities to develop a new class of advanced materials toward a more sustainable future (Hai and Sugimoto, 2018; Dias et al., 2019). Combination of conjugated conducting polymers and cellulose was reported for the first time by Bjorklund and Lundström (1984). In the early days of conducting polymer/ polysaccharides composite research, limited functions were assigned to the fabricated nanocomposite being often used for sensing applications (Kelly et al., 2007). In the early 2010s, chitin was blended with polyaniline (PANI) for humidity sensing applications (Ramaprasad and Rao, 2010). A novel technique for in-situ polymerization of aniline onto chitin was reported by Marcasuzaa et al. (2010) soon afterwards. Recently, chitin and chitosan were used as a biotemplate to fabricate conductive materials based on thiophene (Hai and Sugimoto, 2018). Conductive and luminescent elements were grafted on cellulose via two-step oxidative graft copolymerization of fluorene and thiophene (Phung Hai and Sugimoto, 2017). The control of luminescence and conductivity was achieved varying the fluorene/thiophene ratio. Bhowmik et al. (2016) proposed a vapor deposition polymerization of aniline on cellulose paper via oxidation process. In recent decades, studies toward the fabrication of more robust conductive biomaterials with high mechanical strength, increased flexibility and foldability have been conducted to produce high-performance flexible materials. This contributed to the rapid expansion of the use of nanocellulose as a sustainable substrate for advanced 
applications in the electronics industry. Recently, a homogeneous coating of polypyrrole (PPy) on bacterial cellulose nanofibers was successfully achieved by in-situ chemical polymerization (Lay et al., 2017a). The obtained nanofilms displayed a high conductivity of $1.22{\mathrm{~S} . \mathrm{cm}^{-1}}^{-}$and tensile strength of about 162 MPa. Hafez et al. (2017) and Ko et al. (2017) utilized an environmentally friendly approach to produce nanocellulosebased conductive materials in aqueous solution. $\operatorname{Poly}(3,4-$ ethylenedioxythiophene)/poly(styrene sulfonate) (PEDOT:PSS) acted as conductive layer on the cellulose nanofibers. In another study carried out by Lay et al. (2017b), flexible, lightweight, and strong conductive nanofilms were prepared by cellulose nanofibril (CNF) and PEDOT:PSS mixing followed by in-situ oxidative chemical polymerization of pyrrole. The synergistic effect between PEDOT:PSS and PPy offered high electrical conductivity $\left(\sim 11 \mathrm{~S} . \mathrm{cm}^{-1}\right)$ and specific capacitance $\left(\sim 315 \mathrm{~F} . \mathrm{g}^{-1}\right)$ to the ternary hybrid material. Recent work demonstrated that it is possible graft thiophene by in-situ polymerization onto as-prepare CNF films. According to the authors, the insulating nature of the produced nanocellulose films changed to semiconductor after oxidative polymerization (Dias et al., 2019).

A well-defined core-shell structured PANI/CNF produced strong synergistic interactions with soy protein isolate via tannic acid crosslinking. The interconnected network strategy offered improved electrical conductivity $\left(0.078 \mathrm{~S} . \mathrm{m}^{-1}\right)$, foldability and enhanced structural stability, which make these nanofilms attractive for flexible and green energy-storage systems (Wang Z. et al., 2019). Shimizu et al. (2019) found that the thermal and electrical properties of TONFC films were optimized using a counter-ion exchange process. The thermal conductivity of the TOCNF films increased in the case of the shorter alkyl chain of the quaternary alkyl ammonium. Fu et al. (2020) prepared highly conductive films via pyrrole in-situ polymerization on CNF films by soak and polymerization method. The flexible film exhibited high electrical conductivity of about $24 \mathrm{~S} \mathrm{~cm}^{-1}$, high tensile strength up to $72 \mathrm{MPa}$, and superior thermal stability. In addition, the hybrid nanofilm as a supercapacitor electrode featured a high capacitance and a capacitance retention of $70.5 \%$ after 5,000 cycles. Unuma et al. (2019) investigated the conductivity variation of flexible CNF/ PEDOT: PSS composites in the THz region and how the conductivity can be controlled. The resulting nanofilms exhibited larger carrier densities as the PEDOT: PSS content increased. The classic trade-off between the transparency and conductivity encountered in nanofilms incorporated with carbon materials and conjugated polymers was addressed by Zhang et al. (2020a). The authors were able to fabricate a highly transparent nanofilm (transmittance of about 95\%) with conductivity comparable to those of graphene and PSS: PEDOT. More specifically, TEMPO-mediated oxidation of CNF followed by in-situ photopolymerization of polymerizable deep eutectics solvent (PDES) monomer on its surface were employed in the fabrication of the nanofilm and resulted in exceptional mechanical and electrical durability. The authors revealed negligible effect on the resistance of the transparent nanofilm after 6,000 bending cycles at a $150^{\circ}$ bending angle. In addition, the authors fabricated a robust device assembling the nanofilm into a flexible electroluminescent device as shown in Figure 4.

\section{Combination of Nanocellulose and Conductive Carbon Materials}

Novel carbon materials such as those made of graphene and carbon nanotube (CNT) have received wide attention due to their high surface area, excellent electrical conductivity and ultralight weight (Zheng et al., 2015; Graziano et al., 2020). The combination of nanocellulose and carbon nanoparticles can improve the mechanical and conductive properties of the composite. The simple blend of nanostructured carbon materials and nanocellulose has been conducted over past years. However, the hydrophilic nature of nanocellulose and its marginal affinity with graphene, for example, make the blend method impractical for commercial applications. In this sense, layer-by-layer (LbL) method for the self-assembly of functional materials onto cellulose materials has been accomplished (Hamedi et al., 2013). This technique has the potential to produce thin-film devices with a variety of functions such as gas and chemical sensing and volumetric light emission. Nyström et al. (2015) proposed the construction of a 3D crosslinked nanocellulosebased supercapacitor with carbon nanotube electrodes using a self-assembly method. The resulting aerogels were soft and highly resilient to compression. As an alternative to layer-bylayer assembly technique, a sandwich-structured conductive film (Figure 5) prepared via step-by-step vacuum filtration process exhibited the optimal design in terms of electrical and mechanical performance among the CNF/RGO (cellulose nanofibril/reduced graphene oxide) composites (Hou et al., 2018). The sandwich layers connected in parallel exhibited extraordinary in-plane electrical conductivity of about $4,400 \mathrm{~S} . \mathrm{m}^{-1}$ with only $5 \%$ RGO content.

As reported by Wang R. et al. (2019), conductive paper fabricated by means of ultrafiltration showed exceptional conductivity of about $120 \mathrm{~S} \mathrm{~m}^{-1}$ at $20 \%$ graphene oxide loading. In this study, graphene oxide and cellulose were reduced by green l-ascorbic acid prior to film formation via a one-pot method. The magnitude of conductivity of the fabricated film was similar that of traditional graphene/cellulose composites obtained using multiple steps, hazardous chemicals and very costly procedures (Wang R. et al., 2019). In an intriguing approach, amphiphilic CNF was prepared by TEMPO mediated oxidation and blending graphene with TOCNF (Xu and Hsieh, 2019). They proposed a simple, green, and inexpensive approach using amphiphilic $\mathrm{CNF}$ as multi-functional exfoliating and dispersing material for moisture responsive graphene nanofilm. Amphiphilic CNF performed effectively by associating with graphite through hydrophobic interactions (Figure 6). On the other hand, the hydrophilic surfaces acted as CNF-bound graphene dispersing in water and the charged carboxylates stabilized the CNF-bound graphene dispersions in aqueous solution ( $\mathrm{Xu}$ and Hsieh, 2019). Ardyani et al. (2020) investigated the effect of incorporation of anionic and cationic surfactants in nanocomposites of reduced graphene oxide (RGO) and nanocellulose. This technique increased the electrical conductivity $\left(1.28 \times 10^{-4}{\mathrm{~S} . \mathrm{cm}^{-1}}^{-1}\right)$ of the 


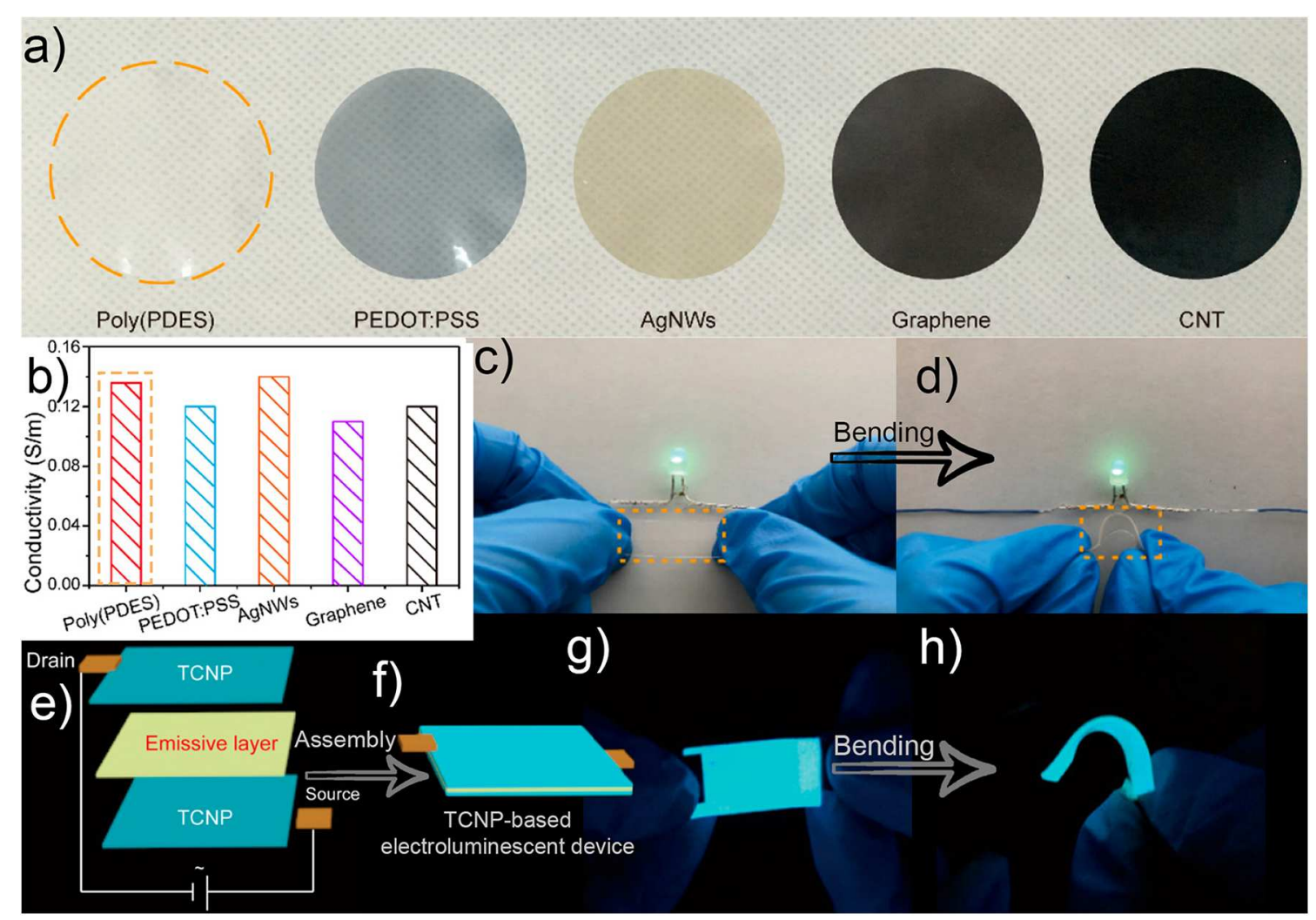

FIGURE 4 | (a) optical photograph and conductivity (b) of nanofilms prepared from CNF with poly(PDES), and other conductive elements; digital photographs of horizontal (c) and curved (d) CNF/poly(PDES) film with the lighting LED; and (f) Schematic illustration of CNF/poly(PDES) flexible electroluminescent devices; and photographs of the flexible CNF/poly(PDES) electroluminescent devices with (g) horizontal, and (h) curved configuration. Adapted with permission from Zhang et al. (2020a). Copyright (2020) American Chemical Society.

nanocomposites since the fractional free volume was reduced due to the enhanced affinity between RGO and nanocellulose. The cationic surfactants exhibited satisfactory ability for stabilization of RGO in CNF since the electrical conductivity of the nanocomposite improved by 143 orders of magnitude when compared to anionic surfactants. Efficient exfoliation of graphene by triethanolamine and subsequently combination with TOCNF resulted in a hybrid nanofilm with enhanced conductivity, mechanical properties, and thermal stability (Zhan et al., 2019). According to the authors, the improved performance is ascribed to the layered hierarchical structure in which TOCNFs were inserted into layers of graphene. The hexagonallayered structure of boron nitride (BN) nanosheets has also attracted attention from academic and industrial perspectives due to their exceptional thermal conductivity and electrically insulating performance. The combination of $\mathrm{BN}$ nanosheets and CNFs has been proposed as flexible substrates to dissipate the heat from printed circuit boards (Hu et al., 2020). A recently discovered family of two-dimensional structure named MXenes have attracted extensive attention due to their metallike electrical conductivity (Tian et al., 2019). In contrast to the chemically inactive and hydrophobic surface of graphene, the hydrophilic nature of MXenes may overcome the weak interaction between different components and also offers good opportunities for the surface functionalization of MXene without compromising its excellent electrical conductivity (Zhao et al., 2018). As reported by Tian et al. (2019), the large number of hydroxyl group of CNFs favored good interfacial interaction with MXene, and their combination offered a nanomaterial with high mechanical strength maintaining a high capacitance of about $300 \mathrm{~F} \mathrm{~g}^{-1}$ and a high conductivity up to $300 \mathrm{~S} \mathrm{~cm}^{-1}$ (Tian et al., 2019). The authors suggested that MXene/CNF hybrid films can be employed for structural energy storage.

\section{Hybrid Conductive Composites Based on Nanocellulose}

Hybrid nanocomposite films made of conducting polymers, graphene and nanocellulose have been extensively studied. Recently, nanocomposites built up of two or more constituent materials have been engineered for targeted applications. Flexible layered films based on CNF, reduced graphene oxide (RGO) and polypyrrole (PPy) were prepared via a facile filtration method (Hou et al., 2019). The optimized layered configuration and the synergistic effects of three components make these hybrid films suitable for supercapacitor electrodes. The sandwich-structured film electrode showed a high specific capacitance about of 

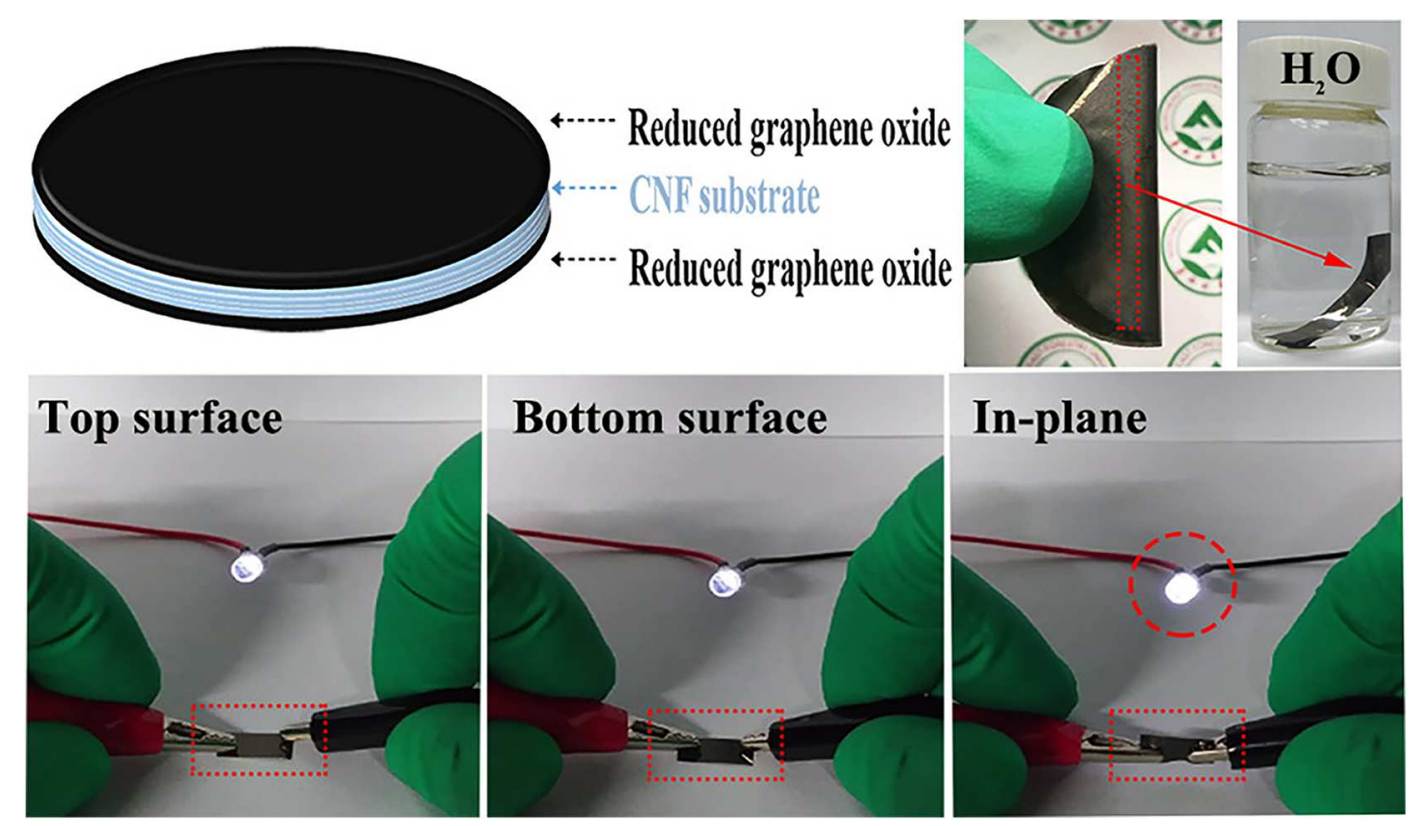

FIGURE 5 | Schematic of the sandwich configuration of the RGO/CNF/RGO nanofilm and LED lamp demonstration in different regions of the film. Reprinted with permission from Hou et al. (2018). Copyright (2018) American Chemical Society.

$300 \mathrm{~F} \mathrm{~g}^{-1}$ and outstanding capacitance retention $(\sim 82 \%$ after 1,000 cycles). Conventional supercapacitors are susceptible to continued mechanical stress and deformations, and normally do not meet the design requirements of flexible wearable electronic devices (Wang et al., 2020a). Flexibility and self-healing capability have been demonstrated as important features, in addition to electrical conductivity, specific capacitance and mechanical robustness. In this context, Wang et al. (2020a) fabricated a coreshell structured TOCNF-CNT/PANI and incorporated it into self-healable PVA hydrogel matrix. As shown in Figure 7, the nanocomposite hydrogel showed excellent flexibility, electrical conductivity of about $15 \mathrm{~S} . \mathrm{m}^{-1}$, and specific capacitance. The nanohybrid hydrogel electrodes exhibited great potential for development of advanced wearable electronic devices. In recent years, some efforts have been devoted to fabricate electrically conductive elastomer nanocomposites based on a natural rubber (NR) matrix. Han et al. (2019b) developed conductive elastomers based on natural rubber and CNF-PANI complexes. The authors demonstrated that the multiple features of the components resulted in a versatile material with high flexibility, strength, stretchability, and conductivity. They suggested that the ternary hybrid nanocomposites could be used as a sensor for human activity monitoring. Besides the electrically conductive capacity of electronic devices, an adequate heat dissipation in flexible electronic devices is crucial for practical applications. In this context, strong anchoring interactions of reduced graphene oxide (rGO) with $\mathrm{Ag}^{+}$as well as the hydrogen bonding interaction between rGO and CNF was achieved by layer-by-layer (LBL) technique (Yang et al., 2020). According to this study, not only was the thermal conductive enhanced but also strength and flexibility. Chen et al. (2015) enhanced the conductivity and thermal stability properties in the final hybrid material. This was achieved upon incorporation of graphene into the conductive cellulose/polypyrrole composite. The obtained composite film was considered appropriate for electrodes due to its high specific capacitance and small impedance at $3.90 \Omega$. The authors suggested that the obtained flexible and lightweight nanocellulose composites could be employed as a supercapacitor component in a wide range of biomedical applications such as electronic skin (Hsu et al., 2019). Han L. et al. (2019) fabricated self-healable, biocompatible, strong and robust films made from CNC or CNF, PPy, and PVA for potential use as artificial electronic skin. The hydrogen bonds and $\mathrm{Fe}^{3+}$ chelation interactions and synergistic effects among the components enhanced the conductivity and mechanical property of the nanocomposite.

Hybrid nanocellulose/PANI/PEDOT core-shell nanorod film has been prepared by in-situ chemical oxidative polymerization. The fabricated nanofilm displayed multicolor changes at different applied potentials, transmittance modulation ability, short response time, and good cycling stability. According to the authors, the fabricated nanofilm has a broad range of applications mostly in smart windows and displays (Zhang S. et al., 2019).

\section{NANOCELLULOSE-BASED LUMINESCENT MATERIALS}

During the recent decades, non-conjugated and conjugated polymers and nanoparticles with different chemical structures emitting colors in the full range of the visible region have been investigated in alternative processes for fabricating light-emitting materials. For the transition from traditional to foldable and 

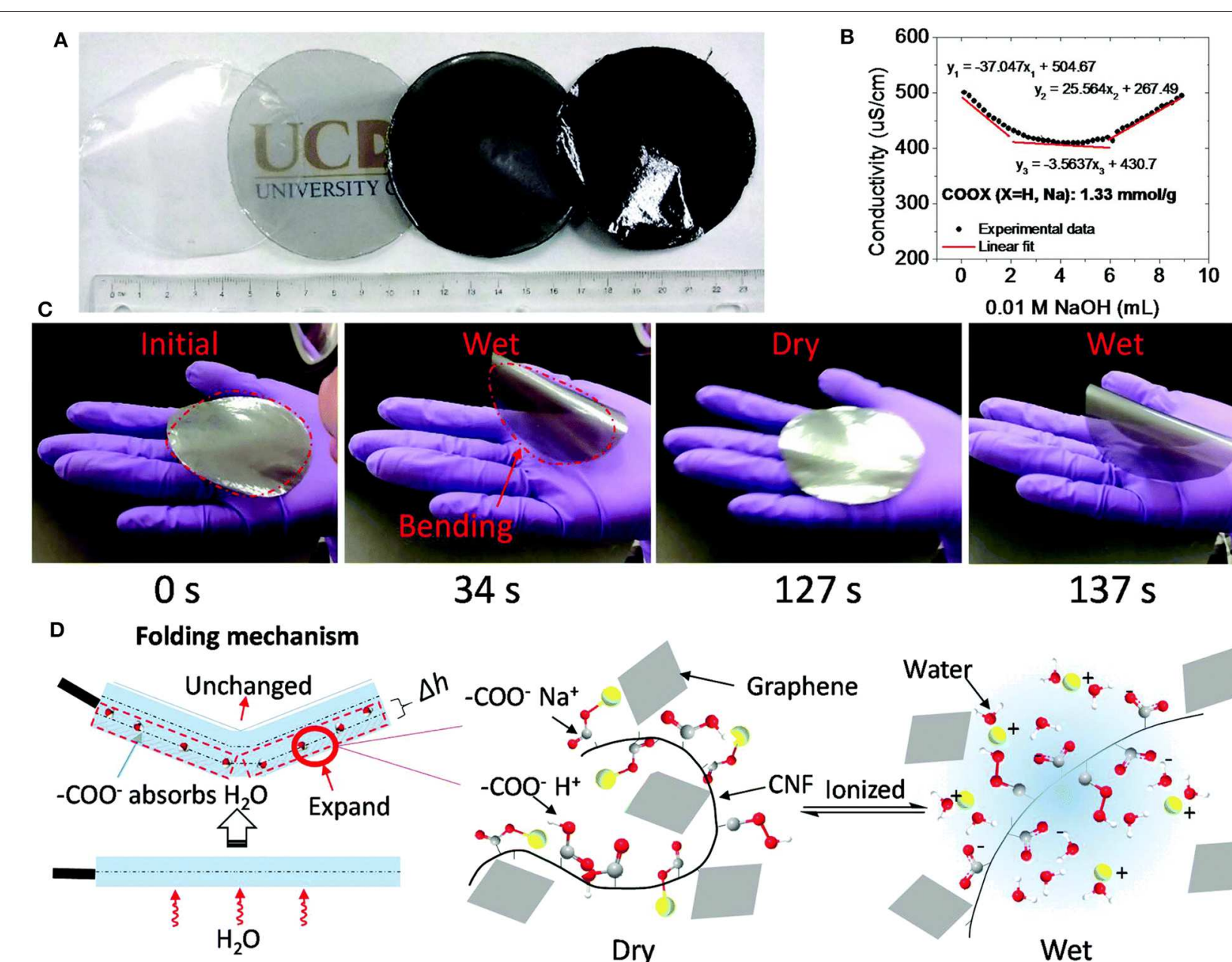

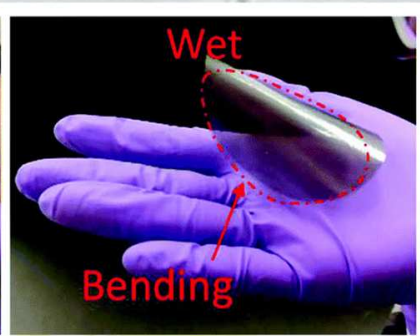

$34 \mathrm{~s}$

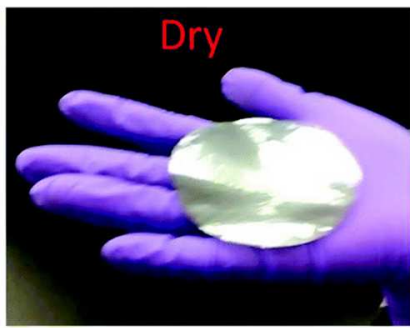

$127 \mathrm{~s}$

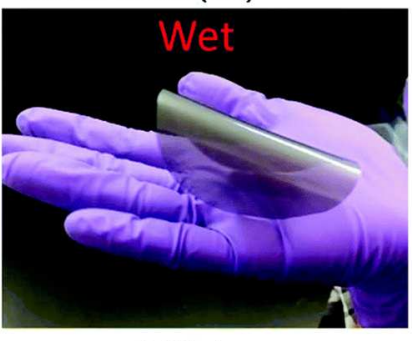

$137 \mathrm{~s}$

D Folding mechanism

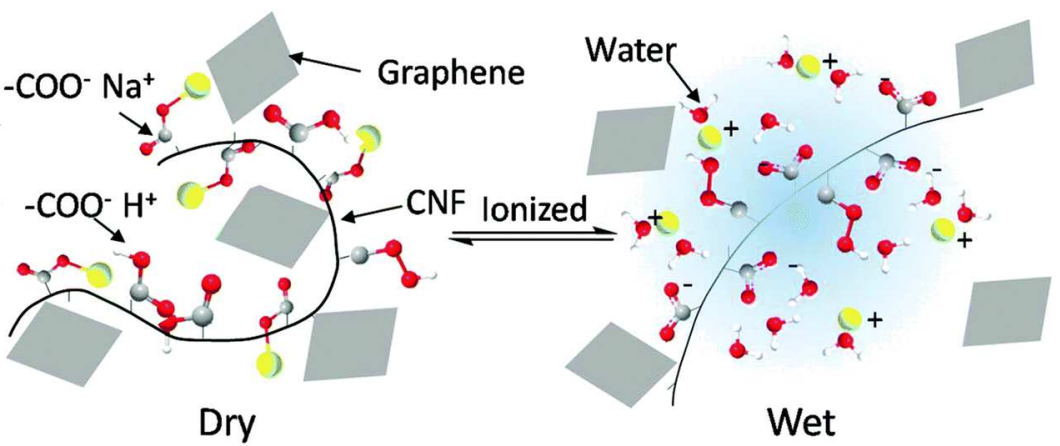

FIGURE 6 | Graphene/CNF film and application in soft robots; (A) image of graphene/CNF films; (B) conductivity of carboxylated charged CNFs; (C) cyclic bending and recovery after exposure to human breaths at times (D) Expansion of CNF chains upon the charged surface groups on CNFs become ionized by water under moisture condition. Reprinted with permission from Xu and Hsieh (2019). Copyright (2019) The Royal Society of Chemistry.

flexible conductive and luminescent devices, new developments of bio-based sensors, organic solar cells, and organic field emission transistors are projected to occur rapidly (Liang et al., 2014; Thomas et al., 2018). Fluorescently functionalized nanocellulose has been developed to expand its feasibility for sophisticated applications such as flexible devices decorated with luminogens elements (Zhang et al., 2017; Li et al., 2019).

\section{Combination of Nanocellulose and Carbon Dots}

Transparent, smooth, and fluorescent nanofilms have been fabricated from nanocellulose-carbon dots (NC-CD). Recently, CDs represent an emerging class of fluorescent materials with broad and strong UV absorbance (Feng et al., 2017). CDs are considered as a potential candidate to replace semiconductor quantum dots in several applications such as sensors, bioimaging, and drug delivery and optoelectronic devices (Jiang et al., 2016). It has been demonstrated that luminescent CDs can be covalently or physically attached to nanocellulose by different ways. The CDs modification not only provides active and anchor sites but also the prevent the agglomerations CDs within nanocellulose films. In 2016, for the first time, CDs were obtained using nanocellulose nanoparticles as the starting material (Jiang et al., 2016). Recently, CDs were obtained via hydrothermal method from pine residues and subsequently combined with PVA and CNF (Xu L. et al., 2020). The same method was used by $\mathrm{Ng}$ et al. (2020) to produce CDs and form a three-dimensional network along with MFC in PVA for building photoluminescent thin film as a tartrazine sensor. The importance of more research to demonstrate the potential of nanocellulose/quantum dot in biosensing applications has been pointed out (Junka et al., 2014). Heavy metal contamination grown as an environmental concern. In this context, Song et al. (2020) developed a CQDs/CNF composite for the adsorption and detection of $\mathrm{Cr}^{3+}$ in water. The authors investigated the synergic effect between adsorption and florescence to real-time monitor the presence of heavy metal. Carbon quantum dots have also been grafted onto oxidized cellulose nanofibrils for $\mathrm{Fe}^{3+}$ ion 

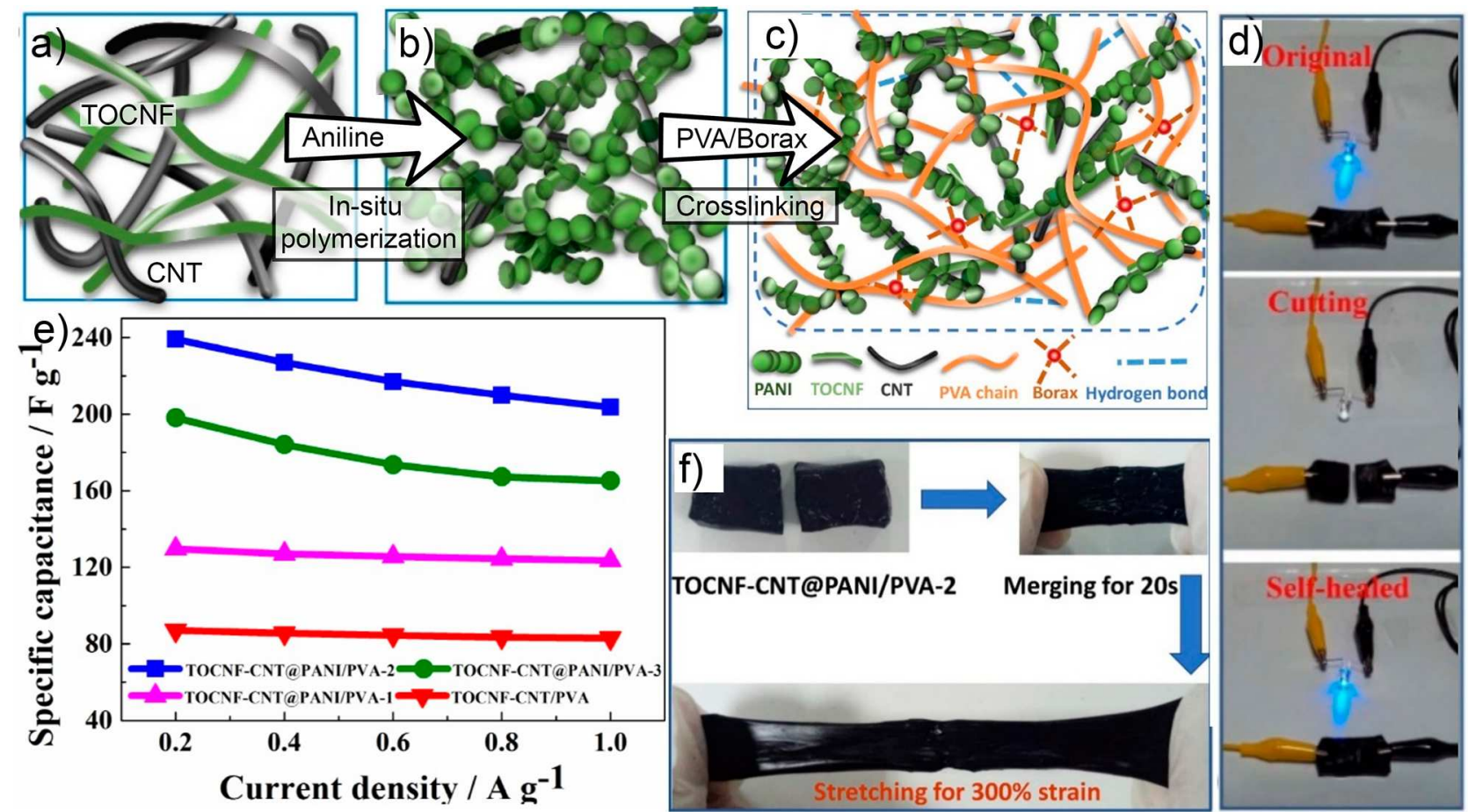

FIGURE 7 | (a) Schematic of TOCNF/CNT composite, (b) aniline polymerization on TOCNF /CNT composite, (c) and (TOCNF/CNT)-PANI/PVA composite hydrogel, (d) optical images of cut and self-healed (TOCNF/CNT)-PANI/PVA hydrogels used to light up a light-emitting diode (LED) circuit, (e) specific capacitance of the hydrogel electrodes (at different PANI/ TOCNF-CNT ratio) under different current densities, and (f) illustration of self-healing property for (TOCNF/CNT)-PANI/PVA hydrogel. Adapted with permission from Wang et al. (2020a). Copyright (2020) MDPI.

detection (Xue et al., 2020). The flexible and photoluminescent nanofilm was fabricated using a one-pot method without the need for any catalyst. Li and $\mathrm{Hu}(2019)$ and Yan et al. (2018) reported a type of multifunctional nanocellulose composite film decorated with CdTe (cadmium telluride) and CdS (cadmium sulfide), respectively. According to the authors, the highly photoluminescent, flexible and strong fabricated nanofilms could be employed for anti-counterfeit marking. Tetsuka (2015) obtained a highly luminescent flexible hybrid nanocomposite composed of amino-functionalized graphene quantum dots/CNF and clay for white-light emitting diodes. In a recent study, the physical interaction of positive charge on chitosan and negative charge on CDs was evaluated as potential green hydrogel for biomedical applications (Konwar et al., 2015). They found that chitosan-carbon dots films exhibited excellent properties such as UV-visible blocking, thermal stability and mechanical strength. According to a recent study, CNCs decorated covalently with $\mathrm{ZnS}$ quantum dots were embedded in PVA matrix to prepare nanocomposite films with antibacterial properties and bright blue fluorescence under the ultraviolet light (Xie et al., 2019). Recently, carbodiimide coupling was used to link CNCs and QDs to fabricate hybrid nanoparticles which can be employed in biological tracking and fluorescent material applications (Abitbol et al., 2017). Furthermore, it has been proposed that luminescent cellulose nanocrystals particles can partially replace carbon nanoparticles by reducing the final cost for the production in potential applications in a variety of fields such as biomedical, photosensors, and photocatalysis (da Silva Souza et al., 2018). Xiong et al. (2019) reported an emissive carbon quantum dots assembled with CNC nanostructure for fabricating flexible robust and strong chiral fluorescent materials. The films became highly fluorescent under alkaline conditions (Figure 8).

As shown is Figure 9, Quraishi et al. (2019) presented highly transparent bio-based hybrid films obtained by carboxylated $\mathrm{CNF}$ and decorated with amino-functional photoluminescent carbon dots. They concluded that the fabricated luminescent hybrid materials are promising candidates for sustainable volumetric display applications. This interesting and valuable technology can be suited to the development of holographic displays (Zhong et al., 2016).

\section{Combination of Nanocellulose and Luminescent Organic Polymers}

Luminescent organic polymers have been reported as an alternative to CDs and metal particle for fluorescent devices (Li et al., 2019). Grigoray et al. (2017) have synthesized a light-responsive pulp fiber with light-controllable mechanical properties decorated with coumarin moieties. Fluorescent CNCs with carbazole and coumarin functionalities were prepared as an invisible security fiber for authenticity indicators that turn visible when being exposed to UV light (Sîrbu et al., 2016). Tong et al. (2020) fabricated a highly transparent hydrophobic 

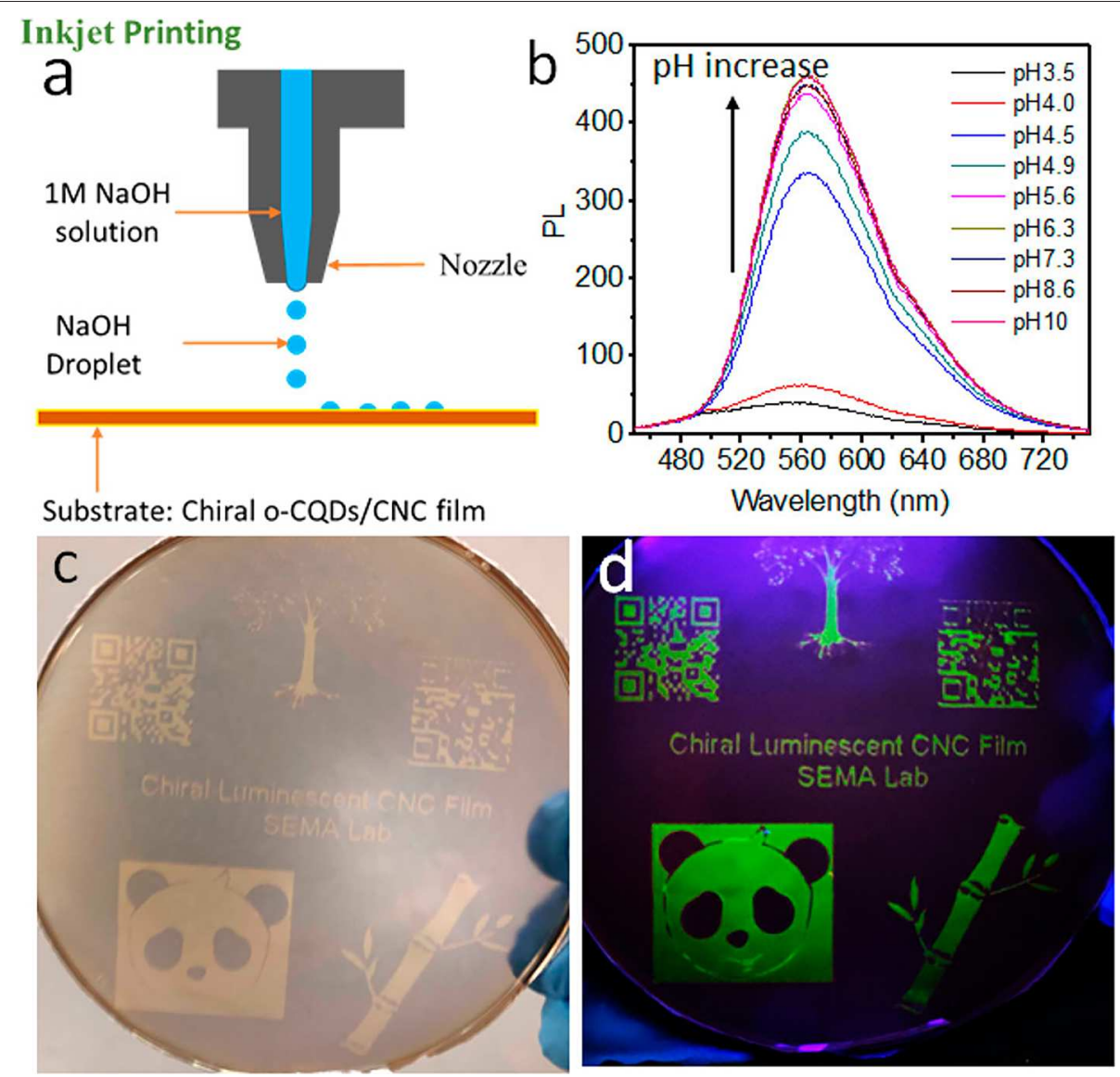

FIGURE 8 | (a) Inkjet printing of luminescent CNC films. (b) Photoluminescent spectra of QD dispersion in different pH conditions. Visual appearance of luminescent CNC films under natural light (c) and UV light (d). Reprinted with permission from Xiong et al. (2019). Copyright (2019) American Chemical Society.

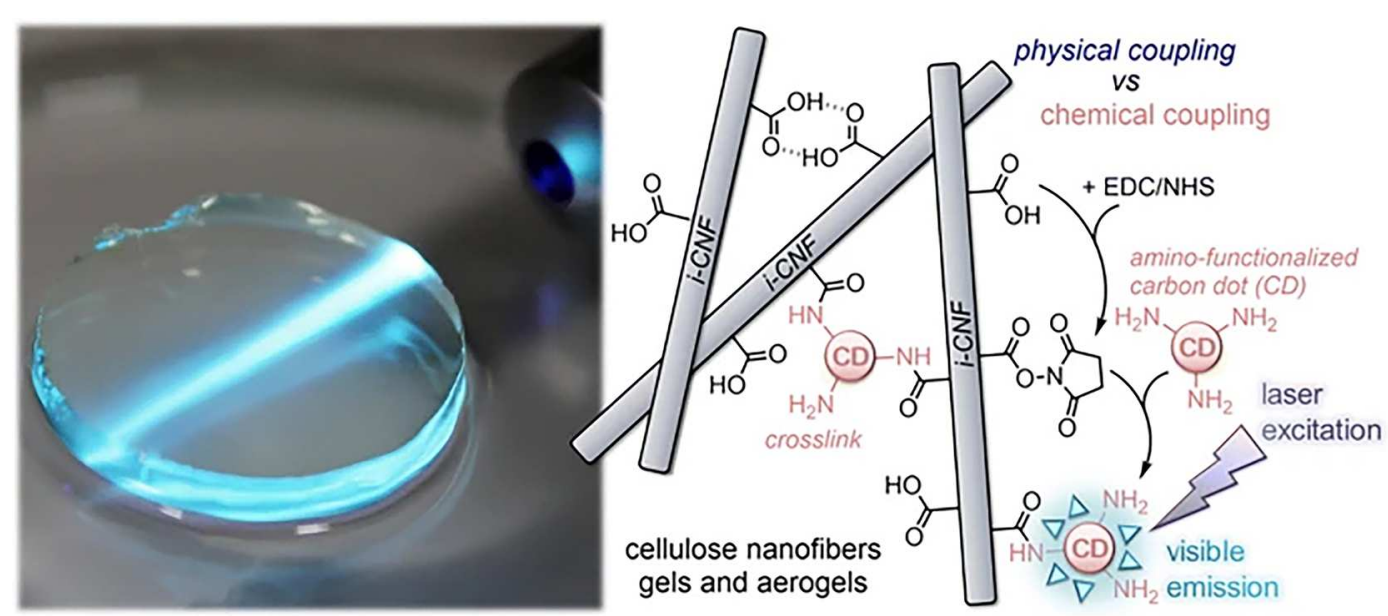

FIGURE 9 | CNF aerogels with covalently coupled CDs under laser beam of $100 \mathrm{~mW}$ at $405 \mathrm{~nm}$ crossing through the soft gels, and scheme showing covalent bonds. Reprinted with permission from Quraishi et al. (2019). Copyright (2019) Springer Nature.

cellulose film for application in flexible electroluminescent devices via free radical polymerization of vinyl-bearing cellulose. The authors suggested that the cellulose functionalized film has great potential applications in flexible transparent electronics. Recently, a fascinating technique was developed by incorporating dioxetanes as stress sensors into polymethyl acrylate/CNCs 
nanocomposite. Intriguingly, the nanocomposite emitted blue light when mechanical force was applied, and the emission intensity varied according to the tensile strain (Chen et al., 2020). The color variations of nanocomposites under different light and temperature conditions have also been explored for display applications. Recently, CNC particles were incorporated into ethylene vinyl alcohol copolymer (EVAL) and the resulting nanocomposite film was subsequently immersed in a solution of a mixture of photochromic/thermochromic powders and epoxy resins (Li et al., 2020). Nanocomposites of PVA and CNC were developed as sensor films which exhibited light emission intensity variations in response to changes in $\mathrm{pH}$ (Schyrr et al., 2014). The allyl functionalized nanocomposites could detect protease activity for applications in wound diagnosis. A simple and low-cost approach for the preparation of a coumarin-TOCNF /PVA membrane with effective fluorescence response was successfully achieved (Zhao et al., 2019). The robust and strong nanocomposite exhibited fluorescence under UV light with potential applications in wound diagnosis and other biomedical technologies. A ratiometric fluorescent nanopaper sensor was investigated and suggested as an artificial tongue for chemical discrimination applications (Abbasi-Moayed et al., 2018). Bacterial cellulose nanopaper as a substrate offered favorable conditions for developing artificial tongues because of its flexibility and transparency. CD grafted with Rhodamine B was incorporated into bacterial nanocellulose, and the resulting film exhibited extraordinary mechanical and physicochemical features for use as a fluorescent sensor for the detection of a variety of heavy metal ions (Abbasi-Moayed et al., 2018). Ionic liquid has also been employed as a green and reusable solvent for CNC film functionalization with amine groups via dipand-pull process (Song et al., 2018). They developed a sensors that can change in color when exposed to formaldehyde and propanal (Song et al., 2018). Hoenders et al. (2018) revealed that tetrazole-functionalized CNF which underwent subsequent functionalization with maleimide-based compound led to selfreporting photo-induced phenomena, making it a promising application for photo-patterning of transparent nanofilm.

\section{Inorganic Hybrid Luminescent Nanocomposites}

Nanocellulose-inorganic hybrid materials have been employed due to the multiple possible functions and synergistic effects among their components. A transparent nanofilm was prepared from TOCNF films with sodium carboxylate groups by immersing the films in nitrate complexes of europium solution (Yang et al., 2018). The strong ionic interactions between the carboxylate groups and $\mathrm{Eu}^{3+}$ ions improved the mechanical properties of the nanofilms. In addition, the exceptional photoluminescence, moisture resistance and thermal stability offered new and exciting opportunities for realizing multifunctional films in electric devices (Yang et al., 2018). Functionalized TOCNF film with stable fluorescence properties was fabricated by in-situ synthesis of a Eu-based metal-organic framework (Wang et al., 2020b). The nanofilm exhibited high selectivity for copper ion detection over a wide range of interfering metal ions. Surface modified $\mathrm{SrAl}_{2} \mathrm{O}_{4}: \mathrm{Eu}^{2+}$, $\mathrm{Dy}^{3+}$ phosphors using (3-aminopropyl) trimethoxy-silane
(APTMS) were incorporated into the TEMPO-oxidized cellulose nanofibril (TOCNF) matrix using a green sol-gel method to fabricate strong and flexible films with long-lasting afterglow luminescence. According to the authors, the resulting flexible, thermal responsive, and light- induced nanocellulose films may open up new possibilities for temperature sensor devices in harsh industrial applications (Zhang L. et al., 2019). In another study, $\mathrm{ZnO} / \mathrm{TONC}$ composite films showed photoluminescence when excited by UV light (Ning et al., 2018). Fedorov et al. (2019) prepared polymer-inorganic films based on CNC and $\mathrm{CNF}$ and strontium fluoride $\left(\mathrm{SrF}_{2}\right)$ : holmium (Ho) powders. According to the authors, the resulting films can be employed for visualization of laser radiation. Zhang et al. (2017) developed transparent and flexible nanofilms from lanthanide complex grafted CNF with ability to absorb and convert UV light into pure red-light emission. Interestingly, the coefficient of thermal expansion (6.39 $\mathrm{ppm} \mathrm{K}^{-1}$ ) of the resulting film was lower than that of films fabricated from fossil-based materials for red light-emitting devices.

\section{PERSPECTIVES AND CONCLUSIONS}

Fascinating biopolymers and sustainable raw materials have been extensively studied in response to a global need for low cost and renewable material as a feedstock for next generation materials. The reinforcing effect of nanocellulose has been frequently employed in less sophisticated products and materials for food applications such as packaging. The energy consumed during nanocellulose fabrication may cause it to be commercially impracticable in its utilization for certain applications. Therefore, it is reasonable to assume that the use of nanocellulose for more complex and sophisticated applications can compensate its actual price and not impose any constraints in the production of highvalue products on a large-scale. In this context, nanocellulose, in the form of nanocrystal or nanofiber, has emerged as a promising material and platform for the next generation of high-performing and energy-related devices. Functionalized nanocellulose can be employed as an alternative to expensive conventional petroleumbased electronic components and devices. Commercialization of the nanocellulose-based advanced materials has been suggested as the next big breakthrough. It is well-known that CNF exhibits outstanding mechanical robustness, flexibility and provides loadbearing ability. In this sense, CNF has been employed to fabricate functional free-standing films, combining multiple features by anchoring nanoparticles either by blending or grafting. On the other hand, the percolation ability of CNC as well as its tunable surface chemistry makes it particularly interesting for the development of functional materials for green and sustainable chemistry, electronics, medicine and food, among others. Having said that, the tradeoff between electrical conductivity and optical transmittance is still a major challenge in exploiting the full potential of nanocellulose-based conductive films. In this context, it is expected that further studies will be conducted to fully integrate nanocellulose-based materials into society and commerce. In terms of luminescent nanocellulose films, the current scenario reveals that substantial effort has been invested in the optical sensing and detection applications. However, it is worth mentioning that a number of studies have focused on more 
sophisticated applications such as screen-printing, mechanoluminescent sensors, and holographic displays. In addition, it was found that TEMPO-mediated oxidation of nanocellulose was extensively used for the development of nanocellulosebased luminescent materials. The current challenge is building high-performance materials almost exclusively constructed from renewable materials. To build flexible and robust devices, multiple components with specific features need to be integrated into a single device. In this context, the combination of features such as conductivity and luminescence is crucial for the next-generation green electronics. In addition, current studies reveal a trend toward renewable materials as starting materials for CDs, CNT, and graphene production. This is particularly important to reduce the carbon footprint without affecting hybrid nanocomposite properties. In this review, a variety of promising and fascinating approaches have been demonstrated. Development of novel bio-based materials demand different features and performance from cellulose based elements. Since it is not feasible fabricate high-performance bio-based devices exclusively made of nanocellulose, the use of nanocellulose as template to control the surface and anchor functional materials

\section{REFERENCES}

Abbasi-Moayed, S., Golmohammadi, H., and Hormozi-Nezhad, M. R. (2018). A nanopaper-based artificial tongue: A ratiometric fluorescent sensor array on bacterial nanocellulose for chemical discrimination applications. Nanoscale 10, 2492-2502. doi: 10.1039/C7NR05801B

Abdul Khalil, H. P. S., Davoudpour, Y., Islam, M. N., Mustapha, A., Sudesh, K., Dungani, R., et al. (2014). Production and modification of nanofibrillated cellulose using various mechanical processes: a review. Carbohydr. Polym. 99, 649-665. doi: 10.1016/j.carbpol.2013.08.069

Abitbol, T., Marway, H. S., Kedzior, S. A., Yang, X., Franey, A., Gray, D. G., et al. (2017). Hybrid fluorescent nanoparticles from quantum dots coupled to cellulose nanocrystals. Cellulose 24, 1287-1293. doi: 10.1007/s10570-016-1188-3

Ahmed, S., and Ikram, S. (2016). Chitosan based scaffolds and their applications in wound healing. Achiev. Life Sci. 10, 27-37. doi: 10.1016/j.als.2016.04.001

Anirudhan, T. S., and Rejeena, S. R. (2014). Poly(acrylic acid-coacrylamide-co-2-acrylamido-2-methyl-1-propanesulfonic acid)-grafted nanocellulose/poly(vinyl alcohol) composite for the in vitro gastrointestinal release of amoxicillin. J. Appl. Polym. Sci. 131, 40699-40710. doi: 10.1002/app.40699

Ardyani, T., Mohamed, A., Abu Bakar, S., Sagisaka, M., Umetsu, Y., Hafiz Mamat, M., et al. (2020). Electrochemical exfoliation of graphite in nanofibrillated kenaf cellulose (NFC)/surfactant mixture for the development of conductive paper. Carbohydr. Polym. 228:115376. doi: 10.1016/j.carbpol.2019.115376

Azeredo, H. M. C., Mattoso, L. H. C., Avena-Bustillos, R. J., Filho, G. C., Munford, M. L., Wood, D., et al. (2010). Nanocellulose reinforced chitosan composite films as affected by nanofiller loading and plasticizer content. J. Food Sci. 75, 1-7. doi: 10.1111/j.1750-3841.2009.01386.x

Bhowmik, K. L., Deb, K., Bera, A., Nath, R. K., and Saha, B. (2016). Charge transport through polyaniline incorporated electrically conducting functional paper. J. Phys. Chem. C 120, 5855-5860. doi: 10.1021/acs.jpcc.5b08650

Bilodeau, M., Moon, R. J., Rudie, A. W., and Bilodeau, M. A. (2014). Production and Applications of Cellulose Nanomaterials. Peachtree Corners, GA: Tappi Press.

Bjorklund, R. B., and Lundström, I. (1984). Some properties of polypyrrole-paper composites. J. Electron. Mater. 13, 211-230. doi: 10.1007/BF02659844

Borges, A. C., Eyholzer, C., Duc, F., Bourban, P.-E., Tingaut, P., Zimmermann, T., et al. (2011). Nanofibrillated cellulose composite hydrogel for the replacement of the nucleus pulposus. Acta Biomater. 7, 3412-3421. doi: 10.1016/j.actbio.2011.05.029 can enhance the performance, add multiple functionalities and consequently expand the uses of nanocellulose-based films while meeting environmental requirement. Herein, we demonstrated that functional nanocellulose will open new opportunities for the design of flexible energy and electronic materials, which is very important in developing the future generation of green materials.

\section{AUTHOR CONTRIBUTIONS}

OD took the lead in writing the manuscript. SK, AL, WY, JT, and MS provided critical feedback and helped shape the research, analysis, and manuscript.

\section{ACKNOWLEDGMENTS}

We are thankful to the Ontario research fund-research excellence (ORF-RE), the natural sciences and engineering research council of Canada (NSERC) and CNPq [Grant number 202275/20159] for the financial supports to carry out this research. Finally, thanks to Onildo Dias Filho for his valuable assistance in the preparation of the illustrations.

Chen, J., Xu, J., Wang, K., Qian, X., and Sun, R. (2015). Highly thermostable, flexible, and conductive films prepared from cellulose, graphite, and polypyrrole nanoparticles. ACS Appl. Mater. Interfaces 7, 15641-15648. doi: 10.1021/acsami.5b04462

Chen, W., Yuan, Y., and Chen, Y. (2020). Visualized bond scission in mechanochemiluminescent polymethyl acrylate/cellulose nanocrystals composites. ACS Macro Lett. 9, 438-442. doi: 10.1021/acsmacrolett.0c00185

Cheng, D., Wen, Y., An, X., Zhu, X., and Ni, Y. (2016). TEMPO-oxidized cellulose nanofibers (TOCNs) as a green reinforcement for waterborne polyurethane coating (WPU) on wood. Carbohydr. Polym. 151, 326-334. doi: 10.1016/j.carbpol.2016.05.083

da Silva Souza, D. R., Caminhas, L. D., de Mesquita, J. P., and Pereira, F. V. (2018). Luminescent carbon dots obtained from cellulose. Mater. Chem. Phys. 203, 148-155. doi: 10.1016/j.matchemphys.2017.10.001

Dias, O. A. T., Konar, S., Leão, A. L., and Sain, M. (2019). Flexible electrically conductive films based on nanofibrillated cellulose and polythiophene prepared via oxidative polymerization. Carbohydr. Polym. 220, 79-85. doi: 10.1016/j.carbpol.2019.05.057

Du, X., Zhang, Z., Liu, W., and Deng, Y. (2017). Nanocellulose-based conductive materials and their emerging applications in energy devices - a review. Nano Energy 35, 299-320. doi: 10.1016/j.nanoen.2017.04.001

Farahbakhsh, N., Roodposhti, P. S., Ayoub, A., Venditti, R. A., and Jur, J. S. (2015). Melt extrusion of polyethylene nanocomposites reinforced with nanofibrillated cellulose from cotton and wood sources. J. Appl. Polym. Sci. 132, 1-10. doi: 10.1002/app.41857

Fedorov, P. P., Luginina, A. A., Kuznetsov, S. V., Voronov, V. V., Lyapin, A. A., Ermakov, A. S., et al. (2019). Composite up-conversion luminescent films containing a nanocellulose and SrF 2 :Ho particles. Cellulose 26, 2403-2423. doi: 10.1007/s10570-018-2194-4

Feng, X., Zhao, Y., Jiang, Y., Miao, M., Cao, S., and Fang, J. (2017). Use of carbon dots to enhance UV-blocking of transparent nanocellulose films. Carbohydr. Polym. 161, 253-260. doi: 10.1016/j.carbpol.2017. 01.030

Fu, Q., Wang, Y., Liang, S., Liu, Q., and Yao, C. (2020). High-performance flexible freestanding polypyrrole-coated CNF film electrodes for allsolid-state supercapacitors. J. Solid State Electrochem. 24, 533-544. doi: 10.1007/s10008-019-04491-3

Fukui, S., Ito, T., Saito, T., Noguchi, T., and Isogai, A. (2018). Counterion design of TEMPO-nanocellulose used as filler to improve properties of hydrogenated acrylonitrile-butadiene matrix. Compos. Sci. Technol. 167, 339-345. doi: 10.1016/j.compscitech.2018.08.023 
Gatenholm, P., and Klemm, D. (2010). Bacterial nanocellulose as a renewable material for biomedical applications. MRS Bull. 35, 208-213. doi: $10.1557 / \mathrm{mrs} 2010.653$

Giese, M., Blusch, L. K., Khan, M. K., Hamad, W. Y., and MacLachlan, M. J. (2014). Responsive mesoporous photonic cellulose films by supramolecular cotemplating. Angew. Chem. Int. Ed. 53, 8880-8884. doi: 10.1002/anie.201402214

Girouard, N., Schueneman, G. T., Shofner, M. L., and Meredith, J. C. (2015). Exploiting colloidal interfaces to increase dispersion, performance, and pot-life in cellulose nanocrystal/waterborne epoxy composites. Polymer 68, 111-121. doi: 10.1016/j.polymer.2015.05.009

Goi, Y., Fujisawa, S., Saito, T., Yamane, K., Kuroda, K., and Isogai, A. (2019). Dual functions of tempo-oxidized cellulose nanofibers in oil-in-water emulsions: a pickering emulsifier and a unique dispersion stabilizer. Langmuir 35, 10920-10926. doi: 10.1021/acs.langmuir.9b01977

Graziano, A., Garcia, C., Jaffer, S., Tjong, J., and Sain, M. (2020). Novel functional graphene and its thermodynamic interfacial localization in biphasic polyolefin systems for advanced lightweight applications. Comp. Sci. Technol. 188:107958. doi: 10.1016/j.compscitech.2019.107958

Grigoray, O., Wondraczek, H., Pfeifer, A., Fardim, P., and Heinze, T. (2017). Fluorescent multifunctional polysaccharides for sustainable supramolecular functionalization of fibers in water. ACS Sustain. Chem. Eng. 5, 1794-1803. doi: 10.1021/acssuschemeng.6b02539

Habibi, Y. (2014). Key advances in the chemical modification of nanocelluloses. Chem. Soc. Rev. 43, 1519-1542. doi: 10.1039/C3CS60204D

Hafez, I., Yang, H.-S., and Tze, W. T. Y. (2017). Mechanically enhanced electrically conductive films from polymerization of 3,4-ethylenedioxythiophene with wood microfibers. J. Appl. Polym. Sci. 134, 45127-45137. doi: 10.1002/app.45127

Hai, T. A. P., and Sugimoto, R. (2018). Surface modification of chitin and chitosan with poly(3-hexylthiophene) via oxidative polymerization. Appl. Surf. Sci. 434, 188-197. doi: 10.1016/j.apsusc.2017. 10.197

Hamedi, M., Karabulut, E., Marais, A., Herland, A., and Nystrçm, G. (2013). nanocellulose aerogels functionalized by rapid layer-by-layer assembly for high charge storage and beyond. Angew. Chem. 52, 12038-12042. doi: 10.1002/anie.201305137

Han, J., Ding, Q., Mei, C., Wu, Q., Yue, Y., and Xu, X. (2019a). An intrinsically self-healing and biocompatible electroconductive hydrogel based on nanostructured nanocellulose-polyaniline complexes embedded in a viscoelastic polymer network towards flexible conductors and electrodes. Electrochim. Acta 318, 660-672. doi: 10.1016/j.electacta.2019.06.132

Han, J., Lu, K., Yue, Y., Mei, C., Huang, C., Wu, Q., et al. (2019b). Nanocellulose-templated assembly of polyaniline in natural rubber-based hybrid elastomers toward flexible electronic conductors. Ind. Crops Prod. 128, 94-107. doi: 10.1016/j.indcrop.2018.11.004

Han, L., Cui, S., Yu, H., Song, M., Zhang, H., Huang, C., et al. (2019). Self-healable conductive nanocellulose nanocomposites for biocompatible electronic skin sensor system self-healable conductive nanocellulose nanocomposites for biocompatible electronic skin sensor system. ACS Appl. Mater. Interfaces 11, 44642-44651. doi: 10.1021/acsami.9b17030

Hoenders, D., Guo, J., Goldmann, A. S., Barner-kowollik, C., and Walther, A. (2018). Materials Horizons Photochemical ligation meets nanocellulose : a versatile platform for self-reporting functional materials. Mater. Horiz. 5, 560-568. doi: 10.1039/C8MH00241J

Hofmann, H. E., and Reid, E. W. (1929). Cellulose acetate lacquers. Ind. Eng. Chem. 21, 955-965. doi: 10.1021/ie50238a017

Hou, M., Xu, M., Hu, Y., and Li, B. (2019). Nanocellulose incorporated graphene/polypyrrole film with a sandwich-like architecture for preparing flexible supercapacitor electrodes. Electrochim. Acta 313, 245-254. doi: 10.1016/j.electacta.2019.05.037

Hou, M., Xu, M., and Li, B. (2018). Enhanced electrical conductivity of cellulose nanofiber/graphene composite paper with a sandwich structure. ACS Sustain. Chem. Eng. 6, 2983-2990. doi: 10.1021/acssuschemeng.7b02683

Hsu, H. H., Khosrozadeh, A., Li, B., Luo, G., Xing, M., and Zhong, W. (2019). An eco-friendly, nanocellulose/rgo/in situ formed polyaniline for flexible and free-standing supercapacitors. ACS Sustain. Chem. Eng. 7, 4766-4776. doi: 10.1021/acssuschemeng.8b04947
Hu, D., Ma, W., Zhang, Z., Ding, Y., and Wu, L. (2020). Dual bioinspired design of highly thermally conductive and superhydrophobic nanocellulose composite films. ACS Appl. Mater. Interfaces 12,11115-11125. doi: 10.1021/acsami.0c01425

Huang, J., Zhu, H., Chen, Y., Preston, C., Rohrbach, K., Cumings, J., et al. (2013). Highly transparent and flexible nanopaper transistors. ACS Nano 7, 2106-2113. doi: $10.1021 / \mathrm{nn} 304407 \mathrm{r}$

Huang, P., Wu, M., Kuga, S., Wang, D., Wu, D., and Huang, Y. (2012). Onestep dispersion of cellulose nanofibers by mechanochemical esterification in an organic solvent. ChemSusChem 5, 2319-2322. doi: 10.1002/cssc.201200492

Jahan, Z., Niazi, M. B. K., and Gregersen, Ø. W. (2018). Mechanical, thermal and swelling properties of cellulose nanocrystals/PVA nanocomposites membranes. J. Ind. Eng. Chem. 57, 113-124. doi: 10.1016/j.jiec.2017.08.014

Jeon, Y.-S., Lowell, A. V., and Gross, R. A. (1999). Studies of starch esterification: reactions with alkenylsuccinates in aqueous slurry systems. Starch Stärke 51, 90-93.

Jiang, Y., Zhao, Y., Feng, X., Fang, J., and Shi, L. (2016). TEMPO-mediated oxidized nanocellulose incorporating with its derivatives of carbon dots for luminescent hybrid films. RSC Adv. 6, 6504-6510. doi: 10.1039/C5RA17242J

Junka, K., Guo, J., Filpponen, I., Laine, J., and Rojas, O. J. (2014). Modification of cellulose nano fi brils with luminescent carbon dots. Biomacromolecules 15 876-881. doi: 10.1021/bm4017176

Kargarzadeh, H., Ioelovich, M., Ahmad, I., Thomas, S., and Dufresne, A. (2017). "Methods for extraction of nanocellulose from various sources," in Handbook of Nanocellulose and Cellulose Nanocomposites, eds H. Kargarzadeh, I. Ahmad, S. Thomas, and A. Dufresne (Weinheim: Wiley-VCH Verlag GmbH \& Co), 1-49.

Kelly, F. M., Johnston, J. H., Borrmann, T., and Richardson, M. J. (2007) Functionalised hybrid materials of conducting polymers with individual fibres of cellulose. Eur. J. Inorg. Chem. 2007, 5571-5577. doi: 10.1002/ejic.200700608

Khalil, H. P. S. A., Bhat, A. H., and Yusra, A. F. I. (2012). Green composites from sustainable cellulose nanofibrils: a review. Carbohydr. Polym. 87, 963-979. doi: 10.1016/j.carbpol.2011.08.078

Ko, Y., Kim, D., Kim, U. J., and You, J. (2017). Vacuum-assisted bilayer PEDOT:PSS/cellulose nanofiber composite film for self-standing flexible, conductive electrodes. Carbohydr. Polym. 173, 383-391. doi: 10.1016/j.carbpol.2017.05.096

Konwar, A., Gogoi, N., Majumdar, G., and Chowdhury, D. (2015). Green chitosancarbon dots nanocomposite hydrogel film with superior properties. Carbohydr. Polym. 115, 238-245. doi: 10.1016/j.carbpol.2014.08.021

Kumari, T. M., Kumar, T. V., and Raghavan, P. (2014). "Nanocellulosebased polymer nanocomposites: an introduction," in Nanocellulose Polymer Nanocomposites, ed V. K. Thakur (Austin, TX: Wiley-Blackwell), 1-15.

Lay, M., González, I., Tarrés, J. A., Pellicer, N., Bun, K. N., and Vilaseca, F. (2017a). High electrical and electrochemical properties in bacterial cellulose/polypyrrole membranes. Eur. Polym. J. 91, 1-9. doi: 10.1016/j.eurpolymj.2017.03.021

Lay, M., Pèlach, M. À., Pellicer, N., Tarrés, J. A., Bun, K. N., and Vilaseca, F. (2017b). Smart nanopaper based on cellulose nanofibers with hybrid PEDOT:PSS/polypyrrole for energy storage devices. Carbohydr. Polym. 165, 86-95. doi: 10.1016/j.carbpol.2017.02.043

Li, M., Li, X., An, X., Chen, Z., and Xiao, H. (2019). Clustering-triggered emission of carboxymethylated nanocellulose. Front. Chem. 7:447. doi: $10.3389 /$ fchem.2019.00447

Li, M., Zhao, X., Li, Y., Wang, W., Zhong, W., Luo, M., et al. (2020). Synergistic improvement for mechanical, thermal and optical properties of PVA-co-PE nanofiber/epoxy composites with cellulose nanocrystals. Compos. Sci. Technol. 188:107990. doi: 10.1016/j.compscitech.2020.107990

Li, X., and Hu, Y. (2019). Luminescent films functionalized with cellulose nanofibrils/CdTe quantum dots for anti-counterfeiting applications. Carbohydr. Polym. 203, 167-175. doi: 10.1016/j.carbpol.2018.09.028

Liang, R., Yan, D., Tian, R., Yu, X., Shi, W., Li, C., et al. (2014). Quantum dots-based flexible films and their application as the phosphor in white light-emitting diodes. Chem. Mater. 26, 2595-2600. doi: 10.1021/cm404218y

Lin, N., Huang, J., and Dufresne, A. (2015). "Polysaccharide nanocrystals-based materials for advanced. Applications," in: Polysaccharide-Based Nanocrystals: Chemistry and Applications, eds J. Huang, P. R. Chang, N. Lin, and A. Dufresne (Weinheim: Wiley-VCH Verlag GmbH \& Co. KGaA), 219-254.

Mandal, A., and Chakrabarty, D. (2015). Characterization of nanocellulose reinforced semi-interpenetrating polymer network of poly (vinyl alcohol) 
\& polyacrylamide composite films. Carbohydr. Polym. 134, 240-250. doi: 10.1016/j.carbpol.2015.07.093

Marcasuzaa, P., Reynaud, S., Ehrenfeld, F., Khoukh, A., and Desbrieres, J. (2010). Chitosan-graft-polyaniline-based hydrogels: elaboration and properties. Biomacromolecules 11, 1684-1691. doi: 10.1021/bm100379z

Martínez Ávila, H., Schwarz, S., Feldmann, E.-M., Mantas, A., von Bomhard, A., Gatenholm, P., et al. (2014). Biocompatibility evaluation of densified bacterial nanocellulose hydrogel as an implant material for auricular cartilage regeneration. Appl. Microbiol. Biotechnol. 98, 7423-7435. doi: $10.1007 / \mathrm{s} 00253-014-5819-\mathrm{z}$

Nair, K. G., Dufresne, A., Gandini, A., and Belgacem, M. N. (2003). Crab shell chitin whiskers reinforced natural rubber nanocomposites. 3. Effect of Chemical modification of chitin whiskers. Biomacromolecules 4, 1835-1842. doi: $10.1021 / \mathrm{bm} 030058 \mathrm{~g}$

Ng, H. K. M., Lim, G. K., and Leo, C. P. (2020). Chemistry N-modified carbon quantum dot in 3D-network of micro fi brillated cellulose for building photoluminescent thin fi $\mathrm{lm}$ as tartrazine sensor. J. Photochem. Photobiol. A 389, 2-9. doi: 10.1016/j.jphotochem.2019.112286

Nguyen, H., Jo, Y. K., Cha, M., Cha, Y. J., Yoon, D. K., Sanandiya, N. D., et al. (2016). Silver nanoparticle composite with improved mechanical properties, electrical conductivity and antibacterial activity. Polymers 8:102. doi: $10.3390 /$ polym 8030102

Ning, R., Takeuchi, M., Lin, J.-M., Saito, T., and Isogai, A. (2018). Influence of the morphology of zinc oxide nanoparticles on the properties of zinc oxide/nanocellulose composite films. React. Funct. Polym. 131, 293-298. doi: 10.1016/j.reactfunctpolym.2018.08.005

Nyström, G., Marais, A., Karabulut, E., Wågberg, L., Cui, Y., and Hamedi, M. M. (2015). Self-assembled three-dimensional and compressible interdigitated thin-film supercapacitors and batteries. Nat. Commun. 6:8259. doi: $10.1038 /$ ncomms 8259

Österberg, M., Vartiainen, J., Lucenius, J., Hippi, U., Seppälä, J., Serimaa, R., et al. (2013). A fast method to produce strong NFC films as a platform for barrier and functional materials. ACS Appl. Mater. Interfaces 5, 4640-4647. doi: $10.1021 / \mathrm{am} 401046 \mathrm{x}$

Peng, X., Ren, J., and Sun, R. (2010). Homogeneous esterification of xylan-rich hemicelluloses with maleic anhydride in ionic liquid. Biomacromolecules 11, 3519-3524. doi: 10.1021/bm1010118

Phung Hai, T. A., and Sugimoto, R. (2017). Photoluminescence control of cellulose via surface functionalization using oxidative polymerization. Biomacromolecules 18, 4011-4021. doi: 10.1021/acs.biomac.7b01067

Pottathara, Y. B., Bobnar, V., Gorgieva, S., Grohens, Y., Finšgar, M., Thomas, S., et al. (2016). Mechanically strong, flexible and thermally stable graphene oxide/nanocellulosic films with enhanced dielectric properties. RSC Adv. 6, 49138-49149. doi: 10.1039/C6RA06744A

Quraishi, S., Plappert, S. F., Grießer, T., Gindl-Altmutter, W., and Liebner, F. W. (2019). Chemical versus physical grafting of photoluminescent aminofunctional carbon dots onto transparent nematic nanocellulose gels and aerogels. Cellulose 26, 7781-7796. doi: 10.1007/s10570-019-02619-2

Raghuwanshi, V. S., and Garnier, G. (2019). Cellulose nano-films as bio-interfaces. Front. Chem. 7:535. doi: 10.3389/fchem.2019.00535

Ramaprasad, A. T., and Rao, V. (2010). Chitin-polyaniline blend as humidity sensor. Sensors Actuat. B Chem. 148, 117-125. doi: 10.1016/j.snb.2010.05.044

Rusmirović, J. D., Ivanović, J. Z., Pavlović, V. B., Rakić, V. M., Rančić, M. P., Djokić, V., et al. (2017). Novel modified nanocellulose applicable as reinforcement in high-performance nanocomposites. Carbohydr. Polym. 164, 64-74. doi: 10.1016/j.carbpol.2017.01.086

Sîrbu, E., Eyley, S., and Thielemans, W. (2016). Coumarin and carbazole fluorescently modified cellulose nanocrystals using a one-step esterification procedure. Can. J. Chem. Eng. 94, 2186-2194. doi: 10.1002/cjce.22624

Sakakibara, K., and Rosenau, T. (2012). Polythiophene-cellulose composites: synthesis, optical properties and homogeneous oxidative co-polymerization. Holzforschung 66, 9-19. doi: 10.1515/HF.2011.137

Schyrr, B., Pasche, S., Voirin, G., Weder, C., Simon, Y. C., and Foster, E. J. (2014). Biosensors based on porous cellulose nanocrystal-poly(vinyl alcohol) scaffolds. ACS Appl. Mater. Interfaces 6, 12674-12683. doi: 10.1021/am502670u

Sethi, J., Farooq, M., Sain, S., Sain, M., Sirvi,ö, J. A., Illikainen, M., et al. (2018). Water resistant nanopapers prepared by lactic acid modified cellulose nanofibers. Cellulose 25, 259-268. doi: 10.1007/s10570-017-1540-2
Shahzamani, M., Taheri, S., Roghanizad, A., Naseri, N., and Dinari, M. (2020) Preparation and characterization of hydrogel nanocomposite based on nanocellulose and acrylic acid in the presence of urea. Int. J. Biol. Macromol. 147, 187-193. doi: 10.1016/j.ijbiomac.2020.01.038

Sharma, S., and Deng, Y. (2016). Dual mechanism of dry strength improvement of cellulose nano fi bril films by polyamide-epichlorohydrin resin cross-linking. Ind. Eng. Chem. Res. 44, 11467-11474. doi: 10.1021/acs.iecr.6b02910

Shi, Z., Phillips, G. O., and Yang, G. (2013). Nanocellulose electroconductive composites. Nanoscale 5, 3194-3201. doi: 10.1039/c3nr00408b

Shimizu, M., Kusumi, R., Saito, T., and Isogai, A. (2019). Thermal and electrical properties of nanocellulose films with different interfibrillar structures of alkyl ammonium carboxylates. Cellulose 26, 1657-1665. doi: 10.1007/s10570-018-2155-y

Song, W., Lee, J. K., Gong, M. S., Heo, K., Chung, W. J., and Lee, B. Y. (2018). Cellulose nanocrystal-based colored thin films for colorimetric detection of aldehyde gases. ACS Appl. Mater. Interfaces 10, 10353-10361. doi: 10.1021 /acsami.7b19738

Song, Z., Chen, X., Gong, X., Gao, X., Dai, Q., Nguyen, T. T., et al. (2020). Luminescent carbon quantum dots/nanofibrillated cellulose composite aerogel for monitoring adsorption of heavy metal ions in water. Opt. Mater. 100:109642. doi: 10.1016/j.optmat.2019.109642

Surov, O. V., Voronova, M. I., Afineevskii, A. V., and Zakharov, A. G. (2018). Polyethylene oxide films reinforced by cellulose nanocrystals: Microstructure-properties relationship. Carbohydr. Polym. 181, 489-498. doi: 10.1016/j.carbpol.2017.10.075

Tan, C., Peng, J., Lin, W., Xing, Y., Xu, K., Wu, J., et al. (2015). Role of surface modification and mechanical orientation on property enhancement of cellulose nanocrystals/polymer nanocomposites. Eur. Polym. J. 62, 186-197. doi: 10.1016/j.eurpolymj.2014.11.033

Tao, J., Wang, R., Yu, H., Chen, L., Fang, D., Tian, Y., et al. (2020). Highly transparent, highly thermally stable nanocellulose/polymer hybrid substrates for flexible OLED devices. ACS Appl. Mater. Interfaces 12, 9701-9709. doi: 10.1021/acsami.0c01048

Tetsuka, H., Nagoya, A., and Asahi, R. (2015). Highly luminescent flexible amino-functionalized graphene quantum dots@cellulose nanofiber-clay hybrids for white-light emitting diodes. J. Mater. Chem. C. 3, 3536-3541. doi: 10.1039/C5TC00250H

Thomas, B., Raj, M. C., Athira, B. K., Rubiyah, H. M., Joy, J., Moores, A., et al. (2018). Nanocellulose, a versatile green platform: from biosources to materials and their applications. Chem. Rev. 118, 11575-11625. doi: 10.1021/acs.chemrev.7b00627

Tian, W., VahidMohammadi, A., Reid, M. S., Wang, Z., Ouyang, L., Erlandsson, J., et al. (2019). Multifunctional nanocomposites with high strength and capacitance using 2d mxene and 1d nanocellulose. Adv. Mater. 31:1902977. doi: 10.1002/adma.201902977

Tong, R., Chen, G., Tian, J., and He, M. (2020). Highly transparent, weakly hydrophilic and biodegradable cellulose film for flexible electroluminescent devices. Carbohydr. Polym. 227:115366. doi: 10.1016/j.carbpol.2019.115366

Trinh, B. M., and Mekonnen, T. (2018). Hydrophobic esterification of cellulose nanocrystals for epoxy reinforcement. Polymer. 155, 64-74. doi: 10.1016/j.polymer.2018.08.076

Tummala, G. K. (2016). "Contact lenses reinforced with nanocellulose," in American Chemical Society National Meeting and Exposition (San Diego, CA). Available online at: http://urn.kb.se/resolve?urn=urn:nbn:se:uu:diva-284940

Unuma, T., Kobayashi, O., Hamdany, I. F. A., Kumar, V., and Saarinen, J. J. (2019). Terahertz complex conductivity of nanofibrillar cellulose-PEDOT:PSS composite films. Cellulose 26, 3247-3253. doi: 10.1007/s10570-019-02276-5

Vaca-Garcia, C., Thiebaud, S., Borredon, M. E., and Gozzelino, G. (1998). Cellulose esterification with fatty acids and acetic anhydride in lithium chloride/N,N-dimethylacetamide medium. J. Am. Oil Chem. Soc. 75, 315-319. doi: 10.1007/s11746-998-0047-2

Vadakkekara, G. J., Thomas, S., and Nair, C. P. R. (2020). Sodium itaconate grafted nanocellulose for facile elimination of lead ion from water. Cellulose 27, 3233-3248. doi: 10.1007/s10570-020-02983-4

Valo, H., Arola, S., Laaksonen, P., Torkkeli, M., Peltonen, L., Linder, M. B., et al. (2013). Drug release from nanoparticles embedded in four different nanofibrillar cellulose aerogels. Eur. J. Pharm. Sci. 50, 69-77. doi: 10.1016/j.ejps.2013.02.023 
Wang, H., Biswas, S. K., Zhu, S., Lu, Y., Yue, Y., Han, J., et al. (2020a). Self-healable electro-conductive hydrogels based on core-shell structured nanocellulose/carbon nanotubes hybrids for use as flexible supercapacitors. Nanomaterials 10:112. doi: 10.3390/nano10010112

Wang, H., Pei, Y., Qian, X., and An, X. (2020b). Eu-metal organic framework @ TEMPO-oxidized cellulose nano fi brils photoluminescence fi $\mathrm{lm}$ for detecting copper ions. Carbohydr. Polym. 236:116030. doi: 10.1016/j.carbpol.2020.116030

Wang, R., Ma, Q., Zhang, H., Ma, Z., Yang, R., and Zhu, J. Y. (2019). Producing conductive graphene-nanocellulose paper in one-pot. J. Polym. Environ. 27, 148-157. doi: 10.1007/s10924-018-1330-4

Wang, T., and Drzal, L. T. (2012). Cellulose-nanofiber-reinforced poly(lactic acid) composites prepared by a water-based approach. ACS Appl. Mater. Interfaces 4, 5079-5085. doi: 10.1021/am301438g

Wang, Y., Gu, F., Ni, L., Liang, K., Marcus, K., Liu, S., et al. (2017). Easily fabricated and lightweight PPy / PDA / AgNW composites for excellent electromagnetic interference shielding. Nanoscale 9, 18318-18325. doi: 10.1039/C7NR05951E

Wang, Z., Tammela, P., Zhang, P., Huo, J., Ericson, F., Strømme, M., et al. (2014). Freestanding nanocellulose-composite fibre reinforced 3D polypyrrole electrodes for energy storage applications. Nanoscale 6, 13068-13075. doi: $10.1039 / C 4 N R 04642 \mathrm{~K}$

Wang, Z., Zhao, S., Huang, A., Zhang, S., and Li, J. (2019). Mussel-inspired codepositing interconnected polypyrrole nanohybrids onto cellulose nanofiber networks for fabricating flexible conductive biobased composites. Carbohydr. Polym. 205, 72-82. doi: 10.1016/j.carbpol.2018.10.016

Wei, J., Chen, Y., Liu, H., Du, C., Yu, H., Ru, J., et al. (2016). Effect of surface charge content in the TEMPO-oxidized cellulose nanofibers on morphologies and properties of poly( $\mathrm{N}$-isopropylacrylamide)-based composite hydrogels. Ind. Crops Prod. 92, 227-235. doi: 10.1016/j.indcrop.2016.08.006

Wu, B., Zhu, G., Dufresne, A., and Lin, N. (2019). fluorescent aerogels based on chemical crosslinking between nanocellulose and carbon dots for optical sensor. ACS Appl. Mater. Interfaces 11, 16048-16058. doi: 10.1021 /acsami.9b02754

Xie, W.-Q., Yu, K.-X., and Gong, Y.-X. (2019). Preparation of fluorescent and antibacterial nanocomposite films based on cellulose nanocrystals/ZnS quantum dots/polyvinyl alcohol. Cellulose 26, 2363-2373. doi: 10.1007/s10570-019-02245-y

Xiong, R., Yu, S., Smith, M. J., Zhou, J., Krecker, M., Zhang, L., et al. (2019). Self-assembly of emissive nanocellulose/quantum dot nanostructures for chiral fluorescent materials. ACS Nano. 13, 9074-9081. doi: 10.1021/acsnano.9b 03305

Xu, H., Xie, Y., Zhu, E., Liu, Y., Shi, Z., Xiong, C., et al. (2020). Supertough and ultrasensitive flexible electronic skin based on nanocellulose/sulfonated carbon nanotube hydrogel films. J. Mater. Chem. A 8, 6311-18. doi: 10.1039/D0TA00158A

Xu, L., Zhang, Y., Pan, H., Xu, N., Mei, C., Mao, H., et al. (2020). Preparation and performance of radiata-pine-derived polyvinyl alcohol/carbon quantum dots fluorescent films. Materials. 13:67. doi: 10.3390/ma13010067

$\mathrm{Xu}, \mathrm{X}$., and Hsieh, Y., Lo (2019). Aqueous exfoliated graphene by amphiphilic nanocellulose and its application in moisture-responsive foldable actuators. Nanoscale 11, 11719-11729. doi: 10.1039/C9NR01602C

Xue, B., Yang, Y., Tang, R., Sun, Y., Sun, S., Cao, X., et al. (2020). One-step hydrothermal synthesis of a flexible nanopaper-based Fe3+ sensor using carbon quantum dot grafted cellulose nanofibrils. Cellulose 27, 729-742. doi: 10.1007/s10570-019-02846-7

Yan, C., yuan, Fang, Z., qiang, Tang, A., min, Liu, W., yu, Liu, Y., and Shi, H., zhen (2018). A tunable optoelectronic nanofibrillated cellulose/CdS quantum dot film with improved transmittance and strength. Cellulose 25, 2405-2417. doi: 10.1007/s10570-018-1727-1

Yang, Q., Zhang, C., Shi, Z., Wang, J., Xiong, C., Saito, T., et al. (2018). Luminescent and transparent nanocellulose films containing europium carboxylate groups as flexible dielectric materials. ACS Appl. Nano Mater. 1, 4972-4979. doi: 10.1021/acsanm.8b01112

Yang, S., Xue, B., Li, Y., Li, X., Xie, L., Qin, S., et al. (2020). Controllable Ag-rGO heterostructure for highly thermal conductivity in layer-by-layer nanocellulose hybrid films. Chem. Eng. J. 383, 1-9. doi: 10.1016/j.cej.2019.123072

Yoo, Y., and Youngblood, J. P. (2016). Green one-pot synthesis of surface hydrophobized cellulose nanocrystals in aqueous medium. ACS Sustain. Chem. Eng. 4, 3927-3938. doi: 10.1021/acssuschemeng.6b00781
Yuan, H., Nishiyama, Y., Wada, M., and Kuga, S. (2006). Surface acylation of cellulose whiskers by drying aqueous emulsion. Biomacromolecules 7, 696-700. doi: $10.1021 / \mathrm{bm} 050828 \mathrm{j}$

Zeng, Z., Wu, T., Han, D., Ren, Q., Siqueira, G., and Nystro, G. (2020). Ultralight, flexible, and biomimetic nanocellulose/silver nanowire aerogels for electromagnetic interference shielding. ACS Nano 3, 2927-2938. doi: 10.1021/acsnano.9b07452

Zhan, Y., Xiong, C., Yang, J., Shi, Z., and Yang, Q. (2019). Flexible cellulose nanofibril/pristine graphene nanocomposite films with high electrical conductivity. Compos. Part A Appl. Sci. Manuf. 119, 119-126. doi: 10.1016/j.compositesa.2019.01.029

Zhang, D., Zhang, Q., Gao, X., and Piao, G. (2013). A nanocellulose polypyrrole composite based on tunicate cellulose. Int. J. Polym. Sci. 2013:175609. doi: $10.1155 / 2013 / 175609$

Zhang, K., Chen, G., Zhao, K., Shen, J., Tian, J., and He, M. (2020a). Facile preparation of highly transparent conducting nanopaper with electrical robustness. ACS Sustain. Chem. Eng. 13, 5132-5139. doi: 10.1021/acssuschemeng. 9 b07266

Zhang, K., Ketterle, L., Järvinen, T., Hong, S., and Liimatainen, H. (2020b). Conductive hybrid fi laments of carbon nanotubes, chitin nanocrystals and cellulose nano fi bers formed by interfacial nanoparticle complexation. Mater. Des. 191:108594. doi: 10.1016/j.matdes.2020.108594

Zhang, L., Lyu, S., Zhang, Q., Wu, Y., Melcher, C., Chmely, S. C., et al. (2019). Dual-emitting film with cellulose nanocrystal-assisted carbon dots grafted SrAl $2 \mathrm{O} 4$, Eu 2+, Dy 3+ phosphors for temperature sensing. Carbohydr. Polym. 206, 767-777. doi: 10.1016/j.carbpol.2018. 11.031

Zhang, S., Chen, S., Zhao, Y., Kang, J., Chen, J., Yan, B., et al. (2019). All-solid-state electrochromic device based on nanocellulose/PANI/PEDOT ternary hybrid system for high optical contrast and excellent cycling stability. J. Electrochem. Soc. 166, H77-H86. doi: 10.1149/2.0751902jes

Zhang, Z., Chang, H., Xue, B., Han, Q., Lü, X., Zhang, S., et al. (2017). New transparent flexible nanopaper as ultraviolet filter based on red emissive $\mathrm{Eu}(\mathrm{III})$ nanofibrillated cellulose. Opt. Mater. 73, 747-753. doi: 10.1016/j.optmat.2017.09.039

Zhao, S., Zhang, H.-B., Luo, J.-Q., Wang, Q.-W., Xu, B., Hong, S. et al. (2018). Highly electrically conductive three-dimensional ti3c2tx mxene/reduced graphene oxide hybrid aerogels with excellent electromagnetic interference shielding performances. ACS Nano 12, 11193-11202. doi: 10.1021/acsnano.8b05739

Zhao, Y., Dang, W., Ma, Q., and Zhu, Y. (2019). Facile preparation of fluorescencelabelled nanofibrillated cellulose (NFC) toward revealing spatial distribution and the interface. Cellulose 26, 4345-4355. doi: 10.1007/s10570-01902404-1

Zheng, Q., Cai, Z., Ma, Z., and Gong, S. (2015). Cellulose nanofibril/reduced graphene oxide/carbon nanotube hybrid aerogels for highly flexible and all-solid-state supercapacitors. ACS Appl. Mater. Interfaces 7, 3263-3271. doi: 10.1021/am507999s

Zhong, H., Wang, Z., Lu, W., Liu, J., and Wang, Y. (2016). "Luminescent materials for 3D Display Technology BT," in Phosphors, Up Conversion Nano Particles, Quantum Dots and Their Applications, Vol. 2, eds R. S. Liu (Singapore: Springer Singapore), 503-523.

Zhu, C., Monti, S., and Mathew, A. P. (2020). Evaluation of nanocellulose interaction with water pollutants using nanocellulose colloidal probes and molecular dynamic simulations. Carbohydr. Polym. 229:115510. doi: 10.1016/j.carbpol.2019.115510

Conflict of Interest: The authors declare that the research was conducted in the absence of any commercial or financial relationships that could be construed as a potential conflict of interest.

Copyright () 2020 Dias, Konar, Leão, Yang, Tjong and Sain. This is an open-access article distributed under the terms of the Creative Commons Attribution License (CC $B Y)$. The use, distribution or reproduction in other forums is permitted, provided the original author(s) and the copyright owner(s) are credited and that the original publication in this journal is cited, in accordance with accepted academic practice. No use, distribution or reproduction is permitted which does not comply with these terms. 